\title{
Processing of subjectively and objectively invisible stimuli in human visual cortex
}

Timo Stein ${ }^{1}$, Daniel Kaiser ${ }^{2}$, Johannes J. Fahrenfort ${ }^{1,3}$, and Simon van Gaal ${ }^{1}$

${ }^{1}$ Brain and Cognition, Department of Psychology, University of Amsterdam, The Netherlands

2 Department of Psychology, University of York, United Kingdom

${ }^{3}$ Cognitive Psychology, Department of Experimental and Applied Psychology, Vrije Universiteit Amsterdam, The Netherlands

\section{Correspondence}

Timo Stein, Brain and Cognition, Department of Psychology, University of Amsterdam, 1001 NK Amsterdam, The Netherlands.

Email: timo@timostein.de 
bioRxiv preprint doi: https://doi.org/10.1101/2020.11.11.376681; this version posted November $11,2020$. The copyright holder for this preprint (which was not certified by peer review) is the author/funder, who has granted bioRxiv a license to display the preprint in perpetuity. It is made available under aCC-BY-ND 4.0 International license.

SUBJECTIVE VS. OBJECTIVE MEASURES OF CONSCIOUSNESS

\section{Abstract}

The study of unconscious processing requires a measure of conscious awareness. Awareness measures can be either subjective (based on participant's report) or objective (based on perceptual performance). The preferred awareness measure depends on the theoretical position about consciousness, and may influence conclusions about the extent of unconscious processing and about the neural correlates of consciousness. We obtained fMRI measurements from 43 subjects while they viewed masked faces and houses that were either subjectively or objectively invisible. We show that neural representations of objectively invisible faces and houses are limited to visual (shape-related) object properties, while subjectively invisible stimuli are processed up to more abstract, categorical levels of representation. These results demonstrate that the hypothesized extent of unconscious information processing is determined by the measurement approach. Furthermore, our data show that subjective and objective approaches are associated with different neural correlates of consciousness and thus have implications for neural theories of consciousness. 


\section{Introduction}

Determining the function and neural correlates of human consciousness is one of the most challenging topics in psychology and cognitive neuroscience today ${ }^{1-3}$. The scientific study of consciousness requires pitting conscious processes against comparable unconscious processes ${ }^{4}$. One powerful approach is to compare neural processing between stimuli presented outside conscious awareness and stimuli that are consciously perceived. Although all major theories of consciousness are based on the notion that stimuli can be processed unconsciously $y^{5-7}$, the scope and extent of unconscious processing are highly debated, with estimates ranging from low-level perceptual analysis ${ }^{8,9}$ to high-level object categorization ${ }^{10-12}$ and full-blown unconscious cognition and reasoning ${ }^{13,14}$. One important cause of this controversy relates to theoretical disagreements about how to measure consciousness and how to demonstrate absence of conscious awareness ${ }^{10,15}$.

The most intuitive approach is to simply ask participants to introspectively report their experience of a barely perceivable (e.g. masked) stimulus ${ }^{16}$. Recent studies adopting such subjective awareness measures found that visual stimuli reported as "invisible" still undergo high-level processing. For example, subjectively invisible stimuli are encoded ${ }^{17,18}$ and stored ${ }^{19-21}$ in visual cortex, enabling above-chance perceptual discrimination even after a memory delay ${ }^{22,23}$. By linking behavioral performance for subjectively invisible stimuli to brain activity, the neural correlates of "blindsight"-like performance can be recorded in normal observers ${ }^{24}$. Subjective measures assume that an observer's decision to report awareness accurately distinguishes the presence vs. absence of conscious perceptual information. However, this assumption is at odds with research on perceptual decision-making, which shows that subjective measures do not accurately reflect perception, because they are susceptible to decision biases ${ }^{25,26}$. Participants often have a conservative bias $^{27}$, such that an "invisible" response merely indicates that a stimulus was relatively difficult to $s^{28} \mathrm{e}^{28}$ Thus, subjective measures may misclassify (partially) conscious stimuli as unconscious. Studies adopting purely subjective measures therefore most likely overestimate the extent of unconscious processing ${ }^{25,29,30}$.

To convincingly rule out conscious perception, objective awareness measures based on performance are required ${ }^{25}$ and crucially, these measures should target the key stimulus characteristic of interest $^{31}$. For example, when contrasting neural responses evoked by masked faces and houses, participant's performance in discriminating the two stimulus categories should not exceed what is expected by chance ${ }^{32}$. Unfortunately, this approach is also riddled with challenges. First, statistically, scientists have taken a failure to reject the null hypothesis (of chance performance, $p>.05$ ) as support for the null hypothesis, which is invalid in the standard frequentist hypothesis testing framework. A non-significant effect can be related to measurement noise and lack of statistical power rather than genuine invisibility (chance performance). In neuroimaging studies in particular, this represents a serious concern as sample sizes tend to be very small (e.g. only four ${ }^{33}$, five ${ }^{32,34}, \operatorname{six}^{35}$, $\operatorname{seven}^{36}$, or eight ${ }^{37}$ 
participants). Further, objective awareness is often only measured "offline" in a block separate from the fMRI recordings (or even outside the MRI scanner) ${ }^{34-41}$, and with considerably fewer trials ${ }^{34,36,38-40}$ and sometimes also fewer participants ${ }^{37,39}$. Given these issues, it is unknown how stimuli that are genuinely invisible according to the objective definition are represented in different cortical areas.

Here, our first goal was thus to measure the extent of unconscious processing of objectively invisible stimuli in human visual cortex. To ensure sufficient statistical power, we included data from 43 human observers who completed a large number of trials while measuring brain activity evoked by masked faces or houses using a multi-band fMRI sequence with fast acquisition time and high spatial resolution. An "online" (trial-by-trial) measure of perceptual discriminability of faces and houses served as an exhaustive ${ }^{31,42}$ measure of objective awareness, leading to equal numbers of trials to calculate objective discrimination performance and to evaluate the extent of neural processing of masked face/house stimuli. Perceptual sensitivity was analyzed with Bayesian statistics to establish genuine objective invisibility.

Compared to subjective invisibility, objective invisibility requires strong reduction of stimulus strength, e.g. by brief presentation times, low contrasts or strong masking, which reduces neural responses. Estimates of unconscious processing, both in behavior and in neural recordings, may thus critically depend on selection and implementation of method and statistics for establishing absence of conscious awareness. However, as objective and subjective awareness measures have not been compared in the same study, it is unclear whether the two approaches are merely associated with quantitative differences (e.g. subjective measures allowing for stronger neural responses to unconscious stimuli) or whether important qualitative differences exist (e.g. subjective measures allowing for unconscious processing of distinct higher-level stimulus properties).

Hence, our second goal was to directly compare the two approaches. We used fMRI to measure brain activity evoked by masked faces or houses that were visible, subjectively invisible, or objectively invisible. In the objective condition, visibility was controlled experimentally by fixing the contrast of the masks. In the subjective condition, visibility was controlled by the participant's response (i.e. visibility became the dependent variable), and mask contrast was continuously adjusted to yield similar proportions of trials rated as subjectively visible and invisible. This approach yielded a similar number of trials for objectively and subjectively invisible stimuli, resulting in similar statistical power to detect neural effects in objective and subjective conditions. Using multivariate pattern discrimination, we tracked neural representations of faces and houses along the visual processing hierarchy, from early visual cortex to object-selective lateral occipital complex ( LOC $^{43,44}$ ), as well as in category-selective regions in the lateral occipital (occipital face area $\mathrm{OFA}^{45}$ and occipital place area $\mathrm{OPA}^{46}$ ) and ventrotemporal cortices (fusiform face area $\mathrm{FFA}^{47}$ and parahippocampal place area $\mathrm{PPA}^{47}$ ). This analysis 
allowed us to establish the level of representation of objectively and subjectively invisible stimuli in human visual cortex.

\section{Results}

On every trial, participants discriminated between faces and houses (objective measure, face/house) and simultaneously indicated stimulus visibility (subjective measure, visible/invisible). Participants were asked to be as accurate as possible, guessing when necessary. For the subjective measure, instructions emphasized that participants should press "visible" even when they had only a vague idea of the stimulus category, and press "invisible" only when they had absolutely no idea of the stimulus category. Thus, subjective invisibility on our binary scale corresponded to the lowest visibility level of more fine-grained visibility scales, such as the four-point Perceptual Awareness Scale (PAS) ${ }^{16}$. Faces and houses were presented for $16.7 \mathrm{~ms}$, sandwiched between masks (Figure 1a). Subjective stimulus visibility was based on the participant's response, while objective stimulus visibility was controlled by the experimenter. In the subjective condition (50\% of trials) mask contrast was adjusted through an adaptive 1-up 1-down "staircase" procedure. Following a "visible" response, mask contrast was increased by $4 \%$, whereas following an "invisible" response, contrast was lowered by $4 \%$. This continuous adjustment was intended to yield a similar number of subjectively-visible (subj-vis) and subjectively-invisible (subj-inv) trials. This allowed us to test the effect of subjective visibility with minimal differences in mask contrast (subj-vis: mean contrast $7.8 \%$, SD 4.4; subj-vis: mean contrast $11.9 \%, S D 4.3)$. In the objective condition (50\% of trials) mask contrast was either low (2\%) to achieve clear stimulus visibility (objectively visible (obj-vis) condition) or high (100\%) to achieve chance-level discrimination (objectively invisible (obj-inv) condition).

Masking-efficiency experiment. We first ran a separate behavioral experiment to measure the influence of mask contrast on perceptual discriminability and to determine optimal mask contrast for objective invisibility $(\mathrm{N}=17$, Figure $\mathbf{1 b}$ ). Face/house discriminability and subjective visibility (Figure 1c) increased similarly with decreasing masking strength $\left(F_{(8,128)}=247.15, p<.001, \eta_{p}^{2}=.94, \mathrm{BF}_{10}=\right.$ $2.07 \times 10^{74}$, and $F_{(8,128)}=215.69, p<.001, \eta_{p}{ }^{2}=.93, \mathrm{BF}_{10}=8.99 \times 10^{69}$, respectively). A set of one-tailed $t$ tests showed significant above-chance performance for all contrasts (all $p<.005$, all $d_{z}>0.75$, all $\mathrm{BF}_{+0}>$ 14 ), except the $100 \%$ contrast $\left(M=0.03, S D=0.41, t_{(16)}=0.26, p=.40, d_{z}=0.06, \mathrm{BF}_{0+}=3.26\right)$. Bayes factor $\left(\mathrm{BF}_{0_{+}}\right)^{1}$ indicated that the null hypothesis of chance performance was about three times more likely than the alternative hypothesis of above-chance performance, which represents "moderate" evidence for

\footnotetext{
${ }^{1}$ Note that Bayes factor was calculated in JASP ${ }^{83}$ with default prior scales (Cauchy distribution, scale 0.707). See the Supplementary material for additional analyses of discrimination performance in the obj-inv condition.
} 
bioRxiv preprint doi: https://doi.org/10.1101/2020.11.11.376681; this version posted November $11,2020$. The copyright holder for this

preprint (which was not certified by peer review) is the author/funder, who has granted bioRxiv a license to display the preprint in perpetuity. It is made available under aCC-BY-ND 4.0 International license.

the null hypothesis ${ }^{48}$. Thus, full mask contrast was necessary to achieve objective invisibility and was therefore used in the following fMRI experiment.

Behavior. In the fMRI experiment $(N=43)$, face/house discriminability $\left(d^{\prime}\right)$ was high in obj-vis $(M=4.50, S D=0.63)$ and in subj-vis trials $(M=3.50, S D=0.93)$ and remained above chance in subj-inv $\left(M=1.20, S D=0.94, t\right.$-test against chance, $t_{(42)}=8.36, p<.001$ (one-tailed), $d_{z}=1.26, \mathrm{BF}_{+0}=8.59 \times 10^{9}$, Figure 1d). Such above-chance performance for subjectively invisible stimuli is often referred to as a blindsight-like phenomenon of unconscious stimulus processing. Importantly, in obj-inv trials discrimination performance $(M=0.02, S D=0.24)$ did not differ significantly from chance (Figure 1e), with moderate evidence for the null hypothesis of chance-level discrimination $\left(t_{(42)}=0.45, p=.33\right.$ (onetailed), $\left.d_{z}=0.07, \mathrm{BF}_{0+}=4.13\right)$. Regarding subjective visibility, participants reported that the stimulus was visible in $94.6 \%$ (SD 5.5) of the obj-vis trials and invisible in $96.3 \%$ (SD 5.1) of the obj-inv trials. In the subj-vis and subj-inv trials mean subjective visibility was by definition $100 \%$ and $0 \%$, respectively, because these trial categories were conditioned on the subjective visibility response. 
bioRxiv preprint doi: https://doi.org/10.1101/2020.11.11.376681; this version posted November 11, 2020. The copyright holder for this preprint (which was not certified by peer review) is the author/funder, who has granted bioRxiv a license to display the preprint in perpetuity. It is made available under aCC-BY-ND 4.0 International license.

a

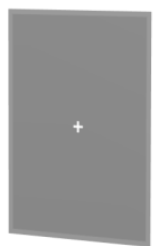

Fixation $292 \mathrm{~ms}$

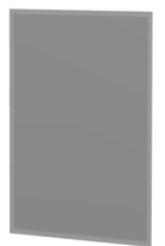

Blank $392 \mathrm{~ms}$

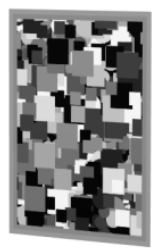

Mask $92 \mathrm{~ms}$

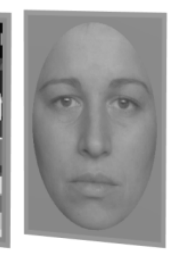

Face or house $16.7 \mathrm{~ms}$

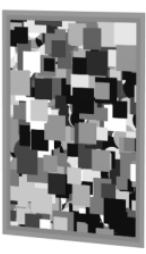

Mask $192 \mathrm{~ms}$

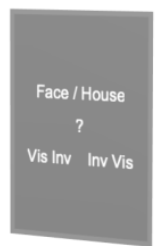

Response $\max .1 .8 \mathrm{~s}$ b

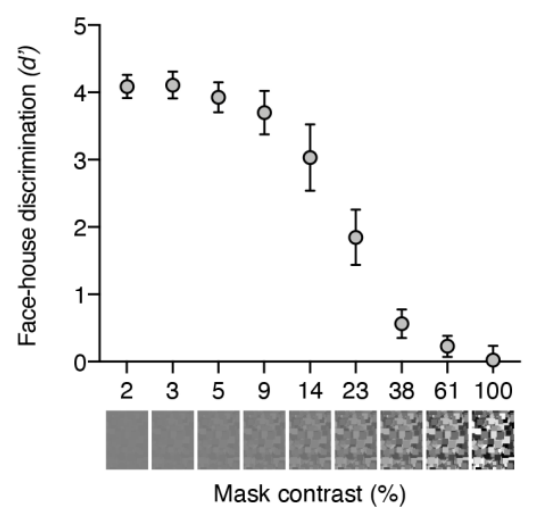

d

fMRI experiment $(N=43)$

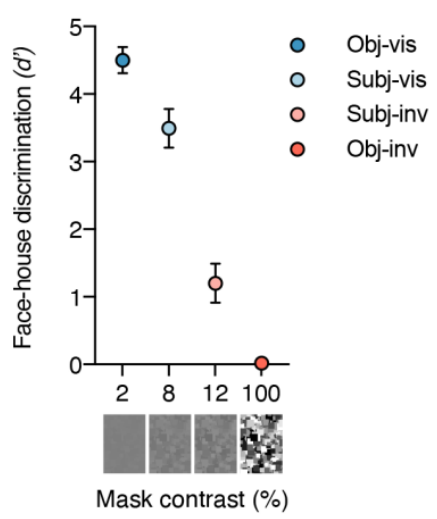

C Behavioral experiment $(N=17)$

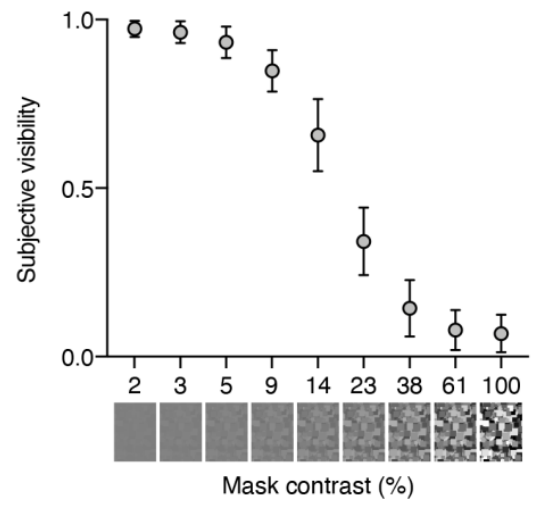

e fMRI obj-inv condition $(N=43)$

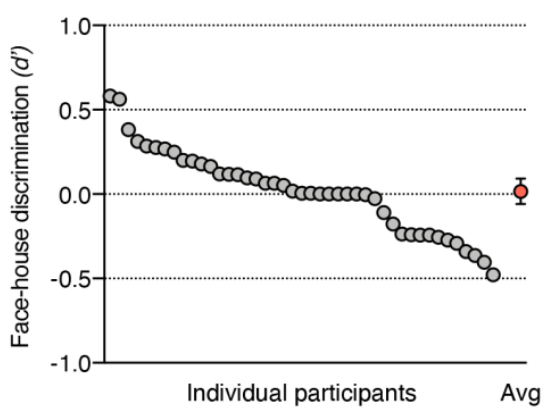

Figure 1. Experimental paradigm, results from the behavioral masking-efficiency experiment, and behavioral results from the fMRI experiment. (a) Example trial: A face or house stimulus was forward and backward masked by a mask with variable contrast, depending on the visibility condition. On every trial, participants judged both the category and visibility of the masked stimulus, yielding measures of objective category discriminability and of subjective stimulus visibility. (b) Results from the behavioral masking-efficiency experiment. Mean face-house discriminability is plotted for nine different masking contrast levels (on a $\log _{10}$ scale). Only with $100 \%$ masking contrast did discriminability not significantly exceed chance performance. (c) Mean visibility ratings from the behavioral masking-efficiency experiment. (d) Behavioral results from the fMRI experiment. Mean face-house discriminability is shown for the four visibility conditions. Mask contrast was set to $2 \%$ in obj-vis and to $100 \%$ in obj-inv; in the subjective conditions, mask contrast was continuously adjusted by an adaptive staircase procedure, which resulted in a mean contrast (across the group) of $8 \%$ in subj-vis, and of $12 \%$ in subj-inv. Discrimination performance was significantly above chance for subjectively 
invisible stimuli (subj-inv) but not for objectively invisible stimuli (obj-inv). All error bars represent 95\% confidence intervals; in (d) for the obj-inv condition the error bar was smaller than the symbol. (e) Individual participant's face-house discrimination performance in the obj-inv condition (in d). Every gray circle represents a participant, the red circle shows the group mean with its $95 \%$ confidence interval.

Category-specific information in visual cortex. We tested in which subregions of visual cortex activation patterns reliably distinguished between faces and houses. To obtain a measure of category information in the neural responses, activity patterns were correlated with "benchmark" patterns for unmasked faces and houses obtained in an independent localizer scan where participants did a simple one-back task on stimuli presented in a block design. This approach is statistically powerful and is often considered to isolate perceptual representations from later cognitive processes related to the task, decision, and motor processes ${ }^{49,50}$. Category information was quantified as the difference between within- and between-category multi-voxel pattern correlations $(\Delta r)$ between the independent localizer and every visibility condition in the main experiment for four separate regions of interest (ROIs, see Figure 2; for complimentary univariate analyses see Supplementary material).

First, we examined activity patterns in primary visual cortex (V1) and object-selective visual cortex (lateral occipital complex $[\mathrm{LOC}]^{43}$ ). There were marked differences between the regions, with as expected overall greater category information in LOC than in $\operatorname{V1}\left(F_{(1,42)}=260.39, p<.001, \eta_{p}{ }^{2}=.86\right.$, $\left.\mathrm{BF}_{10}=4.53 \times 10^{31}\right)$. Category information also differed between visibility conditions $\left(F_{(3,126)}=79.03, p<\right.$ $\left..001, \eta_{p}{ }^{2}=.65, \mathrm{BF}_{10}=1.58 \times 10^{28}\right)$ and these differences were more pronounced in LOC than in V1 (interaction, $F_{(3,126)}=99.86, p<.001, \eta_{p}{ }^{2}=.70, \mathrm{BF}_{10}=1.48 \times 10^{30}$ ). To test whether activity patterns discriminated between faces and houses with above-chance accuracy, separate one-tailed $t$-tests were carried out for every region and every visibility condition. V1 carried significant category information in obj-vis $\left(t_{(42)}=3.44, p<.001, d_{z}=0.52, \mathrm{BF}_{+0}=46.73\right)$, subj-vis $\left(t_{(42)}=3.97, p<.001, d_{z}=0.60, \mathrm{BF}_{+0}=\right.$ $188.02)$ and $o b j-i n v\left(t_{(42)}=2.55, p=.007, d_{z}=0.39, \mathrm{BF}_{+0}=5.74\right)$, but not in subj-inv $\left(t_{(42)}=1.12, p=.135\right.$, $\left.d_{z}=0.17, \mathrm{BF}_{0+}=1.97\right)$. Activity patterns in LOC discriminated between faces and houses with abovechance accuracy in all visibility conditions (obj-vis $\left(t_{(42)}=16.69, p<.001, d_{z}=2.55, \mathrm{BF}_{+0}=2.43 \times 10^{17}\right)$, $\operatorname{subj-vis}\left(t_{(42)}=12.88, p<.001, d_{z}=1.96, \mathrm{BF}_{+0}=3.52 \times 10^{13}\right)$, subj-inv $\left(t_{(42)}=5.21, p<.001, d_{z}=0.80, \mathrm{BF}_{+0}\right.$ $\left.=7.22 \times 10^{3}\right)$ and also in obj-inv $\left(t_{(42)}=3.28, p=.001, d_{z}=0.50, \mathrm{BF}_{+0}=31.19\right)$. Thus, LOC contained category information for both subjectively and objectively invisible stimuli.

To gain insight into the level of representation in higher-level visual cortex, we examined activity patterns in posterior vs. anterior category-selective regions, which are partially overlapping with the spatially extended LOC region (Figure 2). The two more posterior areas represent more basic and "local" visual aspects of faces and houses (occipital face area $\mathrm{OFA}^{45}$ and occipital place area OPA ${ }^{46,51}$ ), whereas the two more anterior areas also contain "global" and abstract categorical representations (fusiform face 
area FFA and parahippocampal place area $\mathrm{PPA}^{47}$ ). Overall, anterior regions carried more category information than posterior regions $\left(F_{(1,42)}=47.09, p<.001, \eta_{p}{ }^{2}=.53, \mathrm{BF}_{10}=4.53 \times 10^{31}\right)$. There were also significant differences between visibility conditions $\left(F_{(3,126)}=63.76, p<.001, \eta_{p}{ }^{2}=.60, \mathrm{BF}_{10}=1.58 \times 10^{28}\right)$ and a significant interaction $\left(F_{(3,126)}=26.94, p<.001, \eta_{p}{ }^{2}=.39, \mathrm{BF}_{10}=1.48 \times 10^{30}\right)$. Activity patterns in the posterior areas (OFA/OPA) discriminated between faces and houses in all conditions (obj-vis $\left[t_{(42)}=\right.$ $\left.10.55, p<.001, d_{z}=1.61, \mathrm{BF}_{+0}=6.99 \times 10^{10}\right]$, subj-vis $\left[t_{(42)}=6.99, p<.001, d_{z}=1.07, \mathrm{BF}_{+0}=1.72 \times 10^{6}\right]$, subj-inv $\left[t_{(42)}=3.90, p<.001, d_{z}=0.59, \mathrm{BF}_{+0}=155.49\right]$ and obj-inv $\left[t_{(42)}=2.72, p=.005, d_{z}=0.42, \mathrm{BF}_{+0}=\right.$ 8.27]). Also in the anterior areas (FFA/PPA) category information was also significant in all visibility conditions. Strong evidence for above-chance discrimination of faces and houses was obtained only for obj-vis $\left(t_{(42)}=11.43, p<.001, d_{z}=1.74, \mathrm{BF}_{+0}=7.89 \times 10^{11}\right)$, subj-vis $\left(t_{(42)}=9.61, p<.001, d_{z}=1.47, \mathrm{BF}_{+0}=\right.$ $\left.4.86 \times 10^{9}\right)$ and subj-inv $\left(t_{(42)}=2.72, p=.005, d_{z}=0.90, \mathrm{BF}_{+0}=5.88 \times 10^{4}\right)$. By contrast, for $o b j$-inv there was no solid evidence for above-chance discrimination in FFA/PPA, with only weak and inconsistent statistical evidence $\left(t_{(42)}=1.97, p=.028, d_{z}=0.30, \mathrm{BF}_{+0}=1.86\right)$.

Differences between visibility conditions. To directly test the effect of different definitions of (in)visibility, we compared activity patterns using paired $t$-tests (two-tailed). Both in V1 and LOC subjective visibility was associated with greater category information than subjective invisibility (V1: $t_{(42)}$ $=2.85, p=.007, d_{z}=0.43, \mathrm{BF}_{10}=5.57$; LOC: $\left.t_{(42)}=9.68, p<.001, d_{z}=1.48, \mathrm{BF}_{10}=3.00 \times 10^{9}\right)$, but this effect was larger in LOC (interaction, $F_{(1,42)}=62.93, p<.001, \eta_{p}{ }^{2}=.60, \mathrm{BF}_{10}=7.99 \times 10^{5}$ ), indicating a greater effect of subjective awareness in object-selective visual cortex than in early visual cortex. Also the way of establishing invisibility influenced the two regions differently (interaction, $F_{(1,42)}=9.02, p=$ $\left..004, \eta_{p}{ }^{2}=.18, \mathrm{BF}_{10}=11.14\right)$. While there was no significant difference in category information between subjectively and objectively invisible stimuli in $\mathrm{V} 1\left(t_{(42)}=-0.73, p=.47, d_{z}=0.11, \mathrm{BF}_{01}=4.72\right)$, in LOC category information was significantly greater for subjectively than for objectively invisible stimuli $\left(t_{(42)}\right.$ $=2.67, p=.011, d_{z}=0.41, \mathrm{BF}_{10}=3.72$ ).

Similar differences were obtained for posterior vs. anterior category-selective regions. Although both posterior and anterior regions carried more category information for subjectively visible than subjectively invisible stimuli (OFA/OPA: $t_{(42)}=4.24, p<.001, d_{z}=0.64, \mathrm{BF}_{10}=195.43$; FFA/PPA: $t_{(42)}=$ $\left.6.42, p<.001, d_{z}=0.98, \mathrm{BF}_{10}=1.49 \times 10^{5}\right)$, this effect was larger in FFA/PPA (interaction, $F_{(1,42)}=11.41$, $p=.002, \eta_{p}{ }^{2}=.21, \mathrm{BF}_{10}=5.66$ ), indicating a greater effect of subjective awareness in anterior than in posterior category-selective regions. Critically, also the method of establishing invisibility had a different effect on the two ROIs (interaction, $F_{(1,42)}=20.43, p<.001, \eta_{p}{ }^{2}=.33, \mathrm{BF}_{10}=28.18$ ). In OFA/OPA there was no significant difference between subjectively and objectively invisible stimuli $\left(t_{(42)}=0.79, p=.44\right.$, $d_{z}=0.12, \mathrm{BF}_{01}=4.50$ ), while FFA/PPA carried more category information for subjectively than for objectively invisible stimuli $\left(t_{(42)}=4.23, p<.001, d_{z}=0.64, \mathrm{BF}_{10}=195.71\right)$. 
a

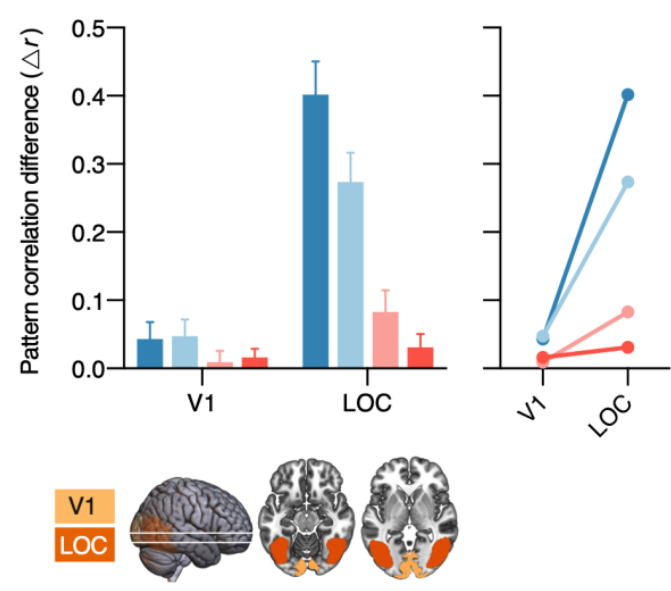

b

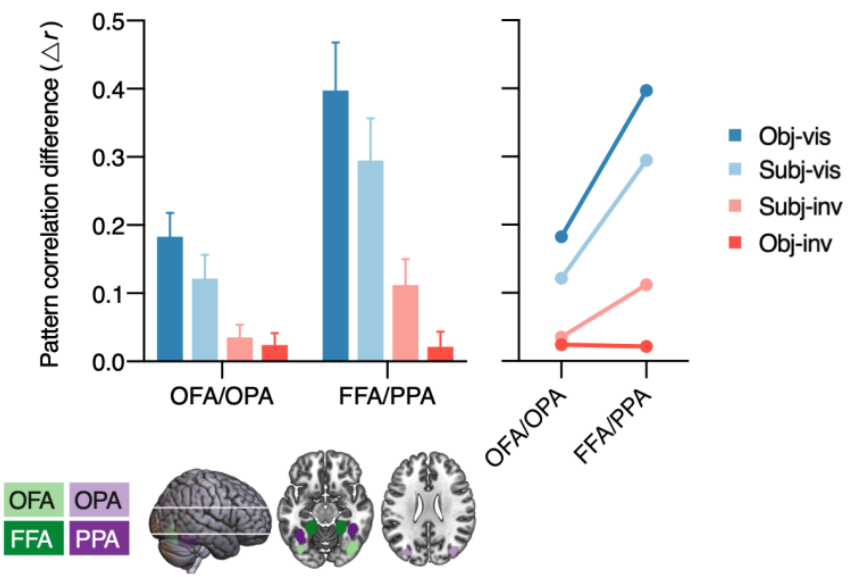

Figure 2. Category information across regions in visual cortex. Multi-voxel pattern correlations between the four visibility conditions in the main experiment and the independent localizer. Bars show the mean difference between within-category and between-category multi-voxel pattern correlations $(\Delta r)$. Error bars represent 95\% confidence intervals. Line plots illustrate the anterior-posterior gradient in category information. (a) Results for early visual cortex (V1) vs. object-selective visual cortex (LOC). (b) Results for posterior categoryselective areas (OFA/OPA) vs. anterior category-selective areas (FFA/PPA).

Posterior-anterior category information gradient. Another way to follow up on the significant visibility $\times$ ROI interactions is to test differences in category information between ROIs, separately for every visibility condition (line plots in Figure 2). For $o b j$-vis, subj-vis, and subj-inv this analysis revealed a posterior-anterior gradient, with increasing category information from V1 to LOC (all $t_{(42)}>4.50, p<$ $.001, d_{z}>0.70, \mathrm{BF}_{10}>596.40$, Figure 2a), and from OFA/OPA to FFA/PPA (all $t_{(42)}=4.45, p<.001, d_{z}>$ $0.67, \mathrm{BF}_{10}>373.24$, Figure $2 \mathbf{b}$ ). For $o b j$-inv, this gradient was not robust. Category information did not differ between V1 and LOC $\left(t_{(42)}>1.70, p=.097, d_{z}=0.26, \mathrm{BF}_{01}=1.63\right)$ or between OFA/OPA and FFA/PPA $\left(t_{(42)}=0.20, p=.842, d_{z}=0.03, \mathrm{BF}_{01}=5.95\right)$, indicating that processing of objectively invisible stimuli is limited to visual shape features.

Whole-brain searchlights. The ROI analyses showed that both subjective visibility (subjectively visible vs. subjectively invisible) and the method for establishing invisibility (subjectively invisible vs. objectively invisible) have the strongest effects in higher-level visual cortex. To further substantiate these findings and to test their spatial specificity, we conducted "searchlight" analyses ${ }^{52}$. These analyses revealed areas carrying significant category information across the whole brain (corrected for multiple comparisons via false discovery estimation $\left.{ }^{53}, p<.05\right)$ in the obj-vis, subj-vis, and subj-inv condition, but not in the obj-inv condition (Figure 3a). In the three former visibility conditions, clusters with significant category information were located in bilateral fusiform gyrus, lingual gyrus, parahippocampal gyrus, and inferior occipital gyrus - areas overlapping with the high-level visual cortical areas defined in our ROI analyses. Compared to subjectively invisible stimuli, subjectively visible stimuli were associated 
bioRxiv preprint doi: https://doi.org/10.1101/2020.11.11.376681; this version posted November 11, 2020. The copyright holder for this preprint (which was not certified by peer review) is the author/funder, who has granted bioRxiv a license to display the preprint in perpetuity. It is made available under aCC-BY-ND 4.0 International license.

with greater category information in the very same regions, and in bilateral fusiform gyrus in particular, thus confirming the results from the ROI analyses (Figure 3b). Additional clusters for subjectively visible stimuli were located in bilateral inferior temporal gyrus, mid occipital gyrus, superior occipital gyrus, left superior parietal lobule, precuneus, and left amygdala. When directly contrasting subjectively invisible with objectively invisible stimuli, there was greater category information for subjectively invisible stimuli in right fusiform gyrus and in left anterior fusiform gyrus extending into left inferior temporal gyrus (Figure 3b).

a Obj-vis Subj-vis
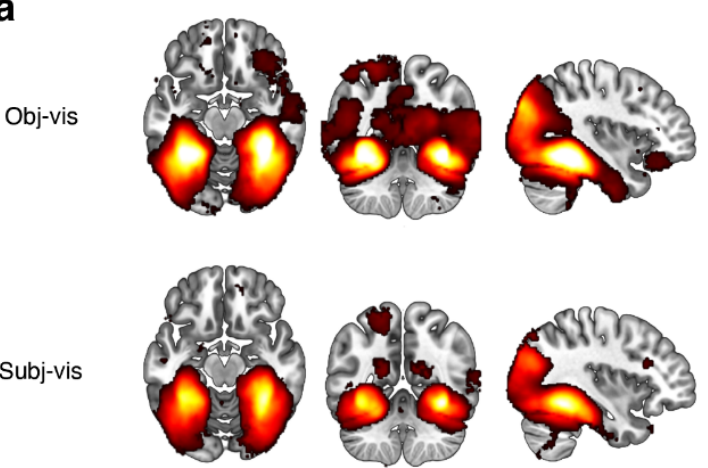

Subj-inv

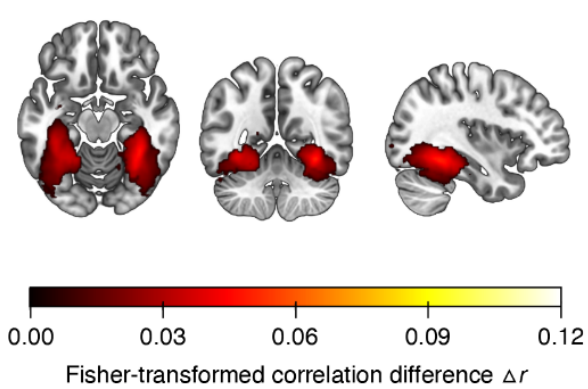

b

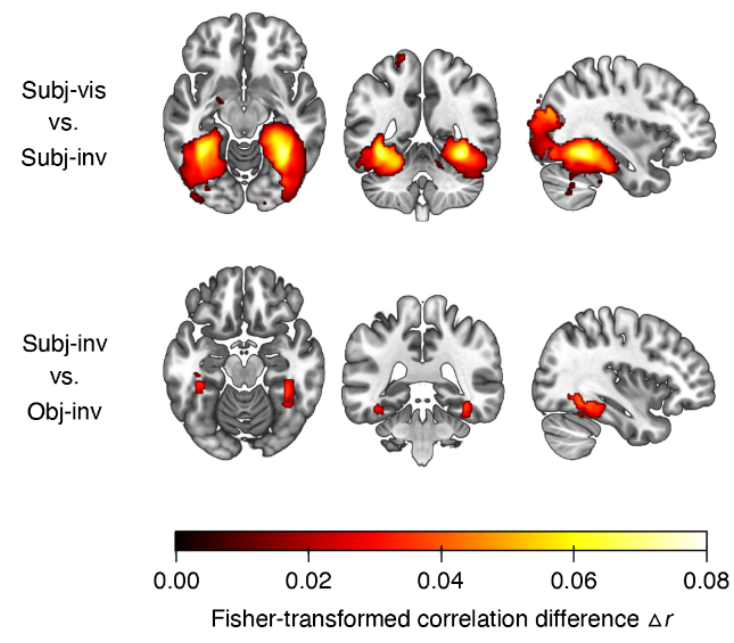

Figure 3. (a) Searchlight results showing clusters with significant category information across the whole brain, separately for the different visibility conditions. Only voxels surviving multiple comparison correction via false discovery estimation ${ }^{53}$ ( $p<.05$ FDR corrected) are shown. For the objectively invisible condition, no clusters survived this statistical threshold. (b) Searchlight results showing the effect of subjective visibility by comparing the subj-vis to the subj-inv condition, and the effect of method for establishing invisibility by comparing the subj-inv to the obj-inv condition.

Correlates of subjective awareness. As mask contrast covaried with subjective visibility, stronger category representations in the subj-vis than in the subj-inv condition could reflect differences in both stimulus strength and subjective awareness. To control for the effect of stimulus strength, we modeled brain responses in the subjective condition (separately for faces and houses) with a parametric regressor reflecting trial-by-trial mask contrast and an additional regressor for visibility (subj-vis, subjinv). The visibility regressor was orthogonalized with respect to the mask-contrast regressor, assigning the mask-contrast regressor all shared variance, such that only variance not explained by the mask- 
bioRxiv preprint doi: https://doi.org/10.1101/2020.11.11.376681; this version posted November 11, 2020. The copyright holder for this preprint (which was not certified by peer review) is the author/funder, who has granted bioRxiv a license to display the preprint in perpetuity. It is made available under aCC-BY-ND 4.0 International license.

contrast regressor was assigned to the visibility-regressor ${ }^{54}$. Note that if fluctuations in subjective awareness and in mask contrast reflected partially shared processes, such as fluctuations in arousal or attention, these would be captured by the mask-contrast regressor, rendering this analysis a conservative approach for determining the neural correlates of subjective awareness.

Multi-voxel pattern correlations between the localizer data and the face-/house patterns adjusted for mask contrast (Figure 4a) revealed strong effects of subjective visibility (one-sample $t$-test, two-tailed) in the more anterior areas $\operatorname{LOC}\left(t_{(42)}=3.57, p<.001, d_{z}=0.54, \mathrm{BF}_{10}=32.03\right)$ and FFA/PPA $\left(t_{(42)}=3.08, p=.004, d_{z}=0.47, \mathrm{BF}_{10}=9.45\right)$, but only inconsistent effects in the more posterior areas $\mathrm{V} 1$ $\left(t_{(42)}=1.96, p=.056, d_{z}=0.30, \mathrm{BF}_{10}=0.94\right)$ and OFA/OPA $\left(t_{(42)}=2.21, p=.033, d_{z}=0.34, \mathrm{BF}_{10}=1.46\right)$. Note, however, that there were no significant differences between posterior and anterior ROIs (both $t_{(42)}$ $\left.<1.37, p>.17, d_{z}<0.21, \mathrm{BF}_{01}>2.57\right)$, limiting claims about the spatial specificity of the effect. To determine whether subjective awareness enhanced category information specifically in occipitotemporal regions, we conducted a whole-brain searchlight analysis using the model controlling for mask contrast. Even at a more liberal statistical threshold ( $p<.001$, uncorrected) this analysis revealed only larger clusters with greater category information in subj-vis than in subj-inv only in bilateral fusiform gyrus (Figure $\mathbf{4 b}$ ) and in bilateral mid occipital gyrus (additional small clusters were located in superior parietal lobule). This further highlights the spatial sensitivity of our effects and the a-priori selection of ROI's.

a

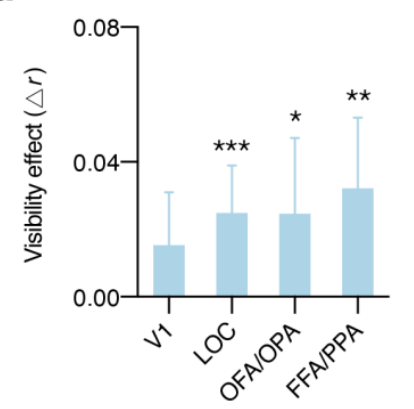

\section{b}

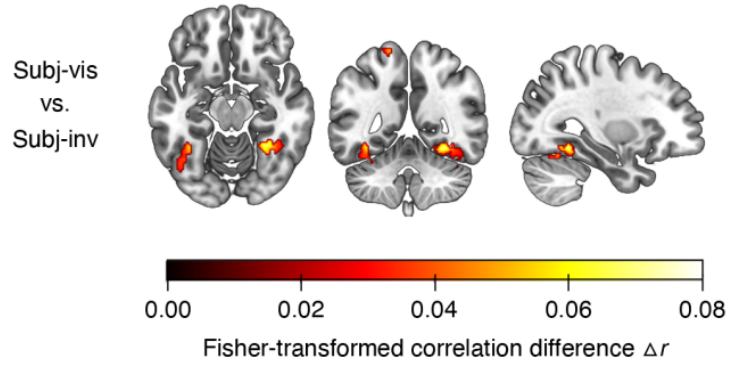

Figure 4. Effect of subjective awareness, adjusted for differences in mask contrast between the subj-vis and subj-inv condition. (a) Difference in multi-voxel pattern correlations $(\Delta r)$ between the subj-vis and subj-inv condition in the four ROls. ${ }^{*} p<.05{ }^{* *} p<.01{ }^{* * *} p<.001$. (b) Searchlight results showing clusters with significantly greater category information in the subj-vis than in the subj-inv condition across the whole brain, controlling for mask contrast. Note that this map is thresholded at $p<.001$, uncorrected.

Correlates of blindsight-like discrimination performance. To test for brain areas involved in blindsight-like unconscious perception ${ }^{24}$, we harnessed the fact that there was considerable interindividual variability in behavioral discriminability of subjectively invisible stimuli (Figure 5a). The phenomenon of blindsight refers to above-chance behavioral performance in the absence of subjective 
bioRxiv preprint doi: https://doi.org/10.1101/2020.11.11.376681; this version posted November 11, 2020. The copyright holder for this preprint (which was not certified by peer review) is the author/funder, who has granted bioRxiv a license to display the preprint in perpetuity. It is made available under aCC-BY-ND 4.0 International license.

awareness of the stimulus on which these behavioral effects are based ${ }^{55}$. For the subj-inv condition, correlations between perceptual discriminability ( $d$, behavioral performance) and category information in ROIs $(\Delta r)$ were significant in LOC $(p<.001)$, OFA/OPA $(p=.028)$ and FFA/PPA $(p=.001)$, but not in V1 $(p=.88)$. One concern with these analyses is that mask contrast in the subj-inv condition was adjusted dynamically for each observer and thus differed between participants. Indeed, mask contrast was (negatively) correlated with behavioral performance $\left(r_{(41)}=-.40, p=.008, \mathrm{BF}_{10}=5.74\right)$. We therefore computed partial correlations between perceptual discriminability and the ROI data, controlling for the effect of mask contrast. As can be seen in Figure 5b, also with this analysis there were significant correlations between discrimination performance and category information in $\operatorname{LOC}\left(r_{(41)}=.38, p=.013\right.$, $\left.\mathrm{BF}_{10}=4.68\right)$ and in FFA/PPA, $\left(r_{(41)}=.38, p=.012, \mathrm{BF}_{10}=4.89\right)$, but the correlation with OFA/OPA was not significant anymore $\left(r_{(41)}=.29, p=.064, \mathrm{BF}_{10}=1.43\right)$. To examine the spatial specificity of these correlations, we calculated a correlation between perceptual discriminability and the subj-inv wholebrain searchlight. Again, even at a liberal statistical threshold $(p<.001$, uncorrected, Figure 5c) this analysis only revealed a cluster in left fusiform gyrus, further indicating the spatial specificity of the results.

a

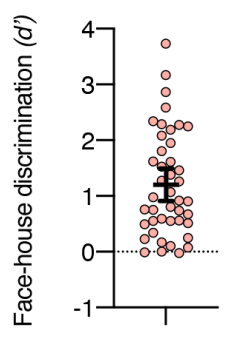

b

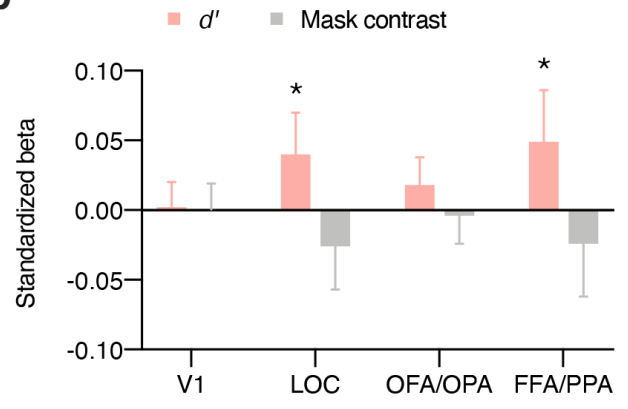

C

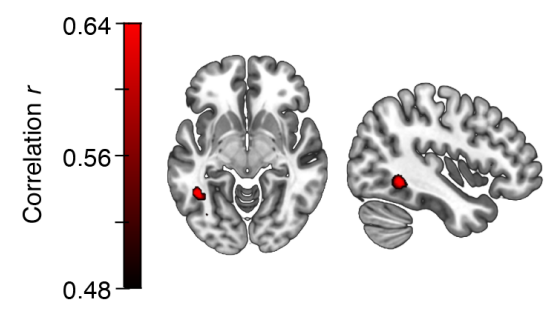

Figure 5. Blindsight-like discrimination of subjectively invisible stimuli. (a) Perceptual discrimination of subjectively invisible stimuli $\left(d^{\prime}\right)$ was highly variable between individuals. Every circle represents a participant; the horizontal bar the mean, and the error bar the 95\% confidence interval. (b) Multiple regression analyses of category information $(\Delta r)$ in the four ROls for the subj-inv condition, showing standardized beta weights for the predictors perceptual discrimination of subjectively invisible stimuli ( $\left.d^{\prime}\right)$ and mask contrast in the subjinv condition. Error bars show $95 \%$ confidence intervals. ${ }^{*} p<.05{ }^{* *} p<.01$. (c) Partial correlation between perceptual discrimination and the subj-inv whole-brain searchlight, adding the effect of mask contrast to the null model. Note that this map is thresholded at $p<.001$, uncorrected.

\section{Discussion}

In the absence of a gold standard for measuring consciousness, scientists are firmly divided into those who use subjective measures based on participant's reported experience and those who use objective measures based on participant's perceptual discrimination performance ${ }^{10,15}$. Subjective measures allow 
for greater stimulus strength (e.g. lower mask contrast) than objective measures and this may result in greater estimates of unconscious processing. Using fMRI we found that although activity patterns in visual cortex carried representations of both subjectively and objectively invisible faces and houses, there were quantitative and qualitative differences between the two approaches. Subjectively invisible stimuli were more strongly represented in object-selective visual cortex than objectively invisible stimuli. For subjectively invisible stimuli, similar to visible stimuli, there was a clear posterior-to-anterior gradient in visual cortex, with stronger category information in ventrotemporal cortex (FFA/PPA) than in occipital cortex (V1, OFA/OPA). For objectively invisible stimuli, category information remained virtually unchanged from early visual cortex to object- and category-selective areas. We interpret this as an indication that representations of objectively invisible stimuli are likely limited to visual (shaperelated) object properties, while subjectively invisible stimuli are processed up to more abstract, categorical levels of representation. These differences in neural processing of subjectively vs. objectively invisible stimuli can account for some of the current controversies on the scope and extent of unconscious processing ${ }^{8,13}$.

Unconscious processing of objectively invisible stimuli has been notoriously difficult to demonstrate. Rendering stimuli perceptually indiscriminable requires very low stimulus strength (e.g. high mask contrast), which strongly reduces neural responses in visual cortex, especially at higher levels in the cortical hierarchy ${ }^{5}$. As a result, the use of objective measures may underestimate unconscious processing. Indeed, several previous fMRI studies failed to obtain visual cortex responses to invisible faces $^{37,56}$, shapes $^{57}$, and objects ${ }^{24,58}$. Here, although maximum mask contrast was required for objective invisibility, perceptually indiscriminable faces and houses still evoked distinct activity patterns in visual cortex. Category information could be decoded from early visual cortex, from object-selective LOC, from the (largely overlapping) category-selective areas in lateral occipital cortex (OFA/OPA), and, less robustly, from ventrotemporal areas (FFA/PPA), while participants were unable to discriminate these categories, thereby satisfying the most rigorous criteria for establishing absence of awareness (see also Figure S1 and accompanying supplementary results and discussion for more details on this issue). Previous fMRI studies that found visual cortex responses to masked stimuli did not convincingly rule out conscious processing because these studies had very small sample sizes ${ }^{32-37}$ and measured awareness with fewer trials ${ }^{34,36,38-41}$ (or even fewer participants ${ }^{37,39}$ ), often in a separate block outside the scanner ${ }^{34-}$ ${ }^{40}$. With low power a non-significant effect in the awareness measure $(p>.05)$ is not surprising and hard to interpret. Even if both the awareness measure and the fMRI data reflected the same underlying (conscious) process, failure to reject the null hypothesis is expected to occur more frequently for the measure with lower power (the awareness measure). To address these concerns, we tested a much larger sample than previous fMRI studies on unconscious processing, collected objective awareness measures on all 200 trials of the objectively invisible condition during scanning, and calculated Bayes factor to 
quantify the evidence favoring the null hypothesis of zero face/house discriminability vs. the alternative hypothesis of above-chance discrimination performance ${ }^{59}$. Finally, no participants or trials needed to be excluded based on high awareness scores. Such data exclusion is a common procedure that risks severely inflating estimates of unconscious processing due to regression to the mean ${ }^{60}$. On a cautionary note, however, although we adopted the highest standards for demonstrating unconscious processing with fMRI to date, our claim of complete absence of awareness depends on specific statistical assumptions such as the prior in Bayesian analyses (see also supplementary results and discussion). Notwithstanding these limitations, our findings provide more conclusive fMRI evidence for unconscious processing of objectively invisible stimuli in human visual cortex.

While representations of objectively invisible stimuli were of similar strength along the posterior-anterior axis from early visual cortex to object- and category-selective areas, subjectively invisible stimuli - similar to visible stimuli - were most strongly represented in category-selective areas in ventrotemporal cortex (FFA/PPA). These differences in neural representation may provide an account for discrepant findings on the influence of unconscious stimuli on behavior, for example in visual priming experiments ${ }^{12,61,62}$. For objectively invisible stimuli our findings predict priming effects based on visual features such as shape, but not based on semantic meaning such as category membership (e.g. gender, emotion, animacy). Indeed, while response priming from objectively invisible shapes (e.g. leftvs. right-pointing arrow ${ }^{63}$, square vs. diamond $\left.{ }^{64}\right)$ is well established, semantic priming from objectively invisible pictures, where visual effects are ruled out (e.g. a picture of an animal priming a word referring to an animal) is heavily debated ${ }^{12,61,62}$. When objective discrimination performance is well above chance, as for subjectively invisible stimuli in the present study, masked primes elicit robust semantic processing $^{65}$. Recent studies indicate that subjectively invisible stimuli reach even higher levels of processing, including crossmodal semantic integration ${ }^{66}$ and working memory ${ }^{67}$. The present findings will resonate with the idea that subjectively invisible stimuli are processed in a way that is qualitatively similar to (clearly) visible stimuli. Studies that establish absence of awareness with subjective measures may thus be expected to conclude that unconscious processes can perform basically the same functions as unconscious processes ${ }^{13}$, thereby challenging influential theories of consciousness such as global workspace theory (GWT) ${ }^{66,67}$.

Activity patterns in LOC and FFA/PPA also predicted perceptual discrimination performance for subjectively invisible stimuli, representing a neural correlate of blindsight-like unconscious perception in healthy human observers ${ }^{24}$. For proponents of the use of subjective measures to study unconscious processes, this could be regarded as strong evidence that unconscious perception shares neural mechanisms with conscious perception, providing further support for the idea that consciousness has little functional role in human perception and cognition ${ }^{13}$. However, for proponents of objective awareness measures above-chance performance for subjectively invisible stimuli simply means that 
these stimuli were in fact not invisible. According to this view, differences in perceptual performance on subjectively invisible trials could reflect differences in response criteria (willingness to say "visible" to barely visible stimuli ${ }^{25,28-31}$ ). In our staircasing procedure, mask contrast was continuously adjusted based on subjective visibility, such that a more liberal criterion (greater willingness to say "visible") would result in higher average mask contrast and this could account for lower performance. Patterns in LOC and FFA/PPA were better predicted by perceptual performance than by mask contrast and perceptual performance explained a significant portion of the neural variance taken into account the variance explained by mask strength. However, without a measure of sensitivity and criterion for the visibility task (e.g. by including stimulus-absent trials) our results cannot rule out criterion effects.

Nevertheless, by comparing stimuli of similar stimulus strength reported as "visible" vs. "invisible", subjective measures have often been adopted to reveal the neural correlates of subjective awareness. Although the contrast of subjectively visible and invisible trials may be confounded with factors unrelated to awareness (e.g. vigilance, attention), many previous fMRI studies adopted this approach, often using binocular rivalry, and typically found stronger visual cortex responses for stimuli reported as visible ${ }^{11}$. Our finding of better pattern discrimination of subjectively visible stimuli in objectand category-selective visual cortex is consistent with the idea that subjective awareness is related to enhanced activity in the very same brain areas that are specialized for processing those stimuli ${ }^{68,69}$. Whether activity in this posterior occipito-temporo-parietal "hot zone"70 is sufficient for awareness, or whether awareness requires additional activity in prefrontal cortex ${ }^{7,71}$, is subject of ongoing debate. Recent studies using so-called "no-report" paradigms indicate that activity in frontal cortex may reflect post-perceptual processes related to reporting awareness rather than to content-specific perceptual awareness per $\mathrm{se}^{72}$. Although establishing absence of awareness on-line during imaging required trialby-trial visibility and discrimination responses, our approach of correlating activity with "benchmark" patterns from an independent localizer scan where participants had a different task, reduced the influence of post-perceptual effects (also see Supplementary material) ${ }^{49,50}$. Isolating perceptual representations in this way, there was no evidence for prefrontal cortex involvement (see Figure S3 and Figure S4 and supplementary results for evidence that activity in a frontoparietal network distinguishes visible vs. invisible conditions, irrespective of stimulus category). As such, these findings support firstorder theories that place the neural correlates of content-specific subjective awareness in sensory $\operatorname{areas}^{6,68-70}$.

The marked differences in neural representation of subjectively vs. objectively invisible stimuli revealed here imply that models where "unconscious processing" is seen as a unitary mechanism or concept, without further specifying how absence of awareness was established, will not provide a good fit to the full range of empirical data. Rendering stimuli subjectively or objectively invisible results in different estimates of unconscious information processing in the human brain. Only subjectively 
invisible, but not objectively invisible stimuli were processed along a posterior-anterior gradient, with greater category information in category-selective ventrotemporal cortex than in occipital cortex. At the same time, we provide the first conclusive evidence that even fully indiscriminable, objectively invisible stimuli can be decoded from patterns of fMRI activity in human visual cortex. Previous studies that made such claims ${ }^{32-37}$ did not convincingly establish absence of awareness during scanning and/or had very low statistical power (small sample sizes), resulting in high probability of false-positives in the fMRI data $^{73}$ and of false-negatives in the awareness measure ${ }^{74,75}$. With greater statistical power we also find that subjective awareness involves enhanced representation in visual cortex but not prefrontal cortex, thus supporting first-order theories of consciousness that place the neural correlates of perceptual awareness in the "back" rather than in the "front" of the brain ${ }^{6,68-70}$.

\section{Methods}

Participants. The experiments were approved by the University of Amsterdam ethics committee. Volunteers were recruited from the University of Amsterdam participant pool. Participants were mostly students who received either course credit or a monetary compensation for their participation. All participants reported normal or corrected-to-normal vision, were naïve to the research question, and provided informed consent. In the fMRI experiment, we scanned 54 participants. Eleven participants were excluded from all data analyses: Three were excluded because they did not finish the experiment, two because their anatomical scans were corrupted, and six because of failure to follow the instructions inside the scanner (very few button presses, holding down the buttons continuously, or reporting stimulus visibility in nearly all trials of the condition with lowest categorization performance). The final sample consisted of 43 participants ( 24 female, mean age 22.7 years, $S D$ 3.9, range 18-37 years). In the behavioral masking-efficiency experiment there were 18 participants, one of which was excluded due to a coding error (unbalanced experimental conditions), resulting in a final sample of 17 participants (12 female, mean age 21.8 years, $S D 4.7$, range 18-31 years).

Stimuli. In the scanner, stimuli were presented on a 32-inch LCD screen for MRI $(1920 \times 1080$ pixel resolution, $120 \mathrm{~Hz}$ refresh rate) seen from a viewing distance of approximately $150 \mathrm{~cm}$ through a mirror mounted on the head coil. The experiment was programmed in Matlab using the Psychtoolbox ${ }^{76}$ functions. Stimulus presentation was synchronized with the 8.3-ms vertical refresh cycle of the screen. Stimuli were ten face photographs of neutral expression from the FACES database ${ }^{77}$, and ten house photographs (taken from the front) selected from the internet (see Supplementary material). This selection was based on informal pilot testing with a larger set of stimulus exemplars. Pilot results indicated that the selected exemplars were best matched on subjective visibility. Photographs were cropped to an oval of $240 \times 336$ pixels containing only the inner features of faces and houses, converted to grayscale, and the oval was assigned identical mean luminance and contrast (in RGB values $M=$ 
$127.5, S D=17.5)$. The remainder of the stimulus rectangle as well as the screen background were midgray (RGB value 127.5). Masks filled the whole stimulus rectangle and consisted of a randomly generated arrangement of overlapping rectangles and - in a lesser number - circles in various sizes and levels of gray. We created a set of 100 masks, from which one forward mask and one backward mask were randomly selected on every trial. The contrast of these masks differed between visibility conditions and varied between $2 \%$ and $100 \%$. Throughout the experiment, all stimuli and masks were presented within a 8 -pixel wide light-gray frame $(248 \times 344$ pixels, RGB value 143$)$.

In the objectively visible (obj-vis) condition, mask contrast was set to $2 \%$ to achieve clear visibility of the face/house stimuli. In the objectively invisible (obj-inv) condition, mask contrast was set to $100 \%$, such that participants' ability to discriminate between faces and houses was expected not to differ significantly different from chance (based on the results from the masking-efficiency experiment). In the subjective condition, mask contrast was adjusted through an adaptive 1-up 1-down staircase procedure: On the first trial of each run, mask contrast started at $18 \%$; following a "visible" response, mask contrast on the next trial was increased by $4 \%$; following an "invisible" response, mask contrast was lowered by $4 \%$ (minimum contrast $2 \%$, maximum contrast $100 \%$ ). This adjustment was intended to yield a roughly similar number of subjectively-visible (subj-vis) trials and subjectively-invisible trials (subj-inv).

Procedure. On every trial, a forward- and backward-masked face or house stimulus was presented and participants indicated stimulus category and visibility. Every trial began with $292 \mathrm{~ms}$ of fixation-on, followed by $392 \mathrm{~ms}$ fixation-off, $92 \mathrm{~ms}$ forward mask, $16.7 \mathrm{~ms}$ face/house stimulus (two screen refresh cycles), and $192 \mathrm{~ms}$ backward mask. Next, a response screen prompted participants to use one of four buttons to indicate stimulus category and visibility, using their left hand for the two left buttons and their right hand for the two right buttons (using a button box inside the scanner and a standard keyboard outside the scanner). The left-most button represented "face, visible", and the other button on the left represented "face, invisible." The right-most button represented "house, visible", and the other button on the right "house, invisible." Pilot experiments had shown that this compound response and response mapping was intuitive, and all participants received extensive training in using the buttons. There was a response window of $1.8 \mathrm{~s}$ in which participants could enter their response. The trial ended with a fixation period of variable (jittered) duration (selected from a uniform distribution between 100 and $900 \mathrm{~ms}$ with as many values as trials per fMRI run or as trials per behavioral experiment). The inter-stimulus interval ranged between 2.9 and $3.7 \mathrm{~s}$ (while brain activity was measured with a fast EPI sequence with a TR of $1.6 \mathrm{~s}$, see below).

Instructions. Before beginning the experiment, participants received detailed written and verbal instructions. They were informed that they would be presented with pictures of faces and houses, and that masking would be used to degrade visibility of these stimuli, such that some of the stimuli 
would be visible and some would be invisible. They were instructed to indicate both stimulus category and visibility using the compound response. Participants were informed that when they had absolutely no idea of what category the stimulus represented (i.e. if they did not see anything that indicated that the picture was a face or a house) they should indicate "invisible" and take a guess. If they had some (vague) idea of what the stimulus category could be they should indicate "visible." Thus, the "invisible" category on this two-point visibility scale corresponded to the lowest visibility level of finer-grained visibility scales, such as the popular four-point Perceptual Awareness Scale (PAS) ${ }^{16}$. Subjectively invisible trials in the present study corresponded to the lowest PAS level "no experience", and subjectively visible trials corresponded to all higher PAS levels, including the second-lowest "brief glimpse" level. Participants were informed about the 1.8-s response window but instructions emphasized that (after practice) this would be more than enough time to provide an accurate response, such that there was no speed pressure, and that responses should be as accurate as possible.

Before entering the scanner, participants completed one practice run at a computer outside the scanner. At the beginning of the fMRI session, an anatomical scan was acquired and participants completed another practice run, which was followed by five runs of the main experiment. fMRI runs started and ended with $6.4 \mathrm{sec}$ of fixation. In the following 160 trials of a run, there were 40 trials of the $o b j$-vis condition, 40 trials of the $o b j$-inv condition, and 80 trials of the subjective condition (here, the number of trials in the subj-vis and subj-inv condition depended on the participant's response). Within each condition, each combination of two stimulus categories (faces, houses) and ten stimulus exemplars occurred equally often. Trial order was randomized. In total, there were 200 trials of the obj-vis condition, 200 trials of the $o b j$-inv condition, and 400 trials of the subjective condition.

Localizer run. At the end of the fMRI session, we acquired a functional localizer scan to localize face- and house-responsive voxels in visual cortex. In the localizer, the same stimulus exemplars as in the main experiment were presented in a standard design for localizing category-selective brain areas: Faces and houses were displayed in separate 16-s blocks, where a series of 16 faces or houses was presented unmasked for $750 \mathrm{~ms}$ each, followed by $250 \mathrm{~ms}$ fixation. There were 20 face blocks and 20 house blocks in alternating order. After every four blocks there were $16 \mathrm{~s}$ of fixation. Within a block, stimulus exemplars were randomly ordered with the constraint that the same exemplar could only be presented two times per block. Participants were instructed to press a button when there was a repetition of an exemplar (we did not record these button presses).

fMRI acquisition. MRI data were collected using a 3 Tesla Philips Achieva MRI scanner with a 32- channel head coil. At the beginning of the fMRI session, an anatomical scan was acquired using a T1-weighted gradient-echo sequence (220 slices, voxel size $\left.=1 \mathrm{~mm}^{3}\right)$. Functional images were acquired using a T2*-weighted multiband EPI sequence (56 slices, flip angle $70^{\circ}$, TR $1600 \mathrm{~ms}$, TE $30 \mathrm{~ms}$, voxel 
size $2 \mathrm{~mm}^{3}$ ). During the main experiment, 348 volumes were recorded per run (for a total of 5 runs lasting 9:30 min each), and 248 volumes during the localizer run (lasting 6:30 $\mathrm{min}$ ).

Behavioral masking-efficiency experiment. The masking-efficiency experiment was conducted to determine the required masking settings to achieve objective invisibility, i.e. a masking setting at which participants' ability to discriminate between faces and houses was not significantly above chance. Stimuli were presented on a 24-inch LCD screen $(1920 \times 1080$ pixel resolution, $120 \mathrm{~Hz}$ refresh rate) seen from a free viewing distance of approximately $80 \mathrm{~cm}$. The masking-efficiency experiment was identical to the fMRI experiment, except that nine fixed masking strengths $\left(\log _{10}\right.$-scale between $2 \%$ and $100 \%$ contrast) were used. There were 540 trials, in which each combination of two stimulus categories (faces, houses), ten stimulus exemplars, and nine masking strengths $(2,3.3,5.3,8.7$, $14.1,23.1,37.6,61.3,100 \%$ ) occurred equally often. Trial order was randomized, and there were three obligatory breaks.

\section{Analyses}

Behavioral data. Trials with no response (on average less than 3\%) were excluded from analyses of behavior and fMRI. We calculated the signal detection theory (SDT) sensitivity index $d$ ' as a measure of objective perceptual discriminability of faces and houses: "Face" responses were coded as hits in face trials and as false alarms in house trials. Hit and false alarm rates of 0 or 1 were converted to $1 /(2 N)$ and $1-1 /(2 N)$, respectively, with $N$ being the number of trials on which the rates were based ${ }^{26}$. Finally, the $z$-transformed false alarm rate was then subtracted from the $z$-transformed hit rate to yield $d$.

fMRI data pre-processing. Neuroimaging data were pre-processed using fMRIPrep 1.3.2 ${ }^{78}$. For the structural images, pre-processing steps included: intensity non-uniformity correction, skull stripping, surface reconstruction, spatial normalization to the ICBM 2009c Nonlinear Asymmetrical template version $2009 \mathrm{c}^{79}$ (with nonlinear registration), and brain tissue segmentation. Pre-processing steps for the functional images included: susceptibility distortion correction, co-registration to the structural image, estimation of head-motion parameters, resampling of the BOLD time-series to the template, and high-pass filtering (using a discrete cosine filter with 128 s cut-off).

fMRI data modeling. SPM12 was used to fit a general linear model (GLM) to the data from the localizer run, and to the data for each run of the main experiment. For the localizer, the GLM contained two regressors (faces, houses) and six regressors of no interest (head motion parameters). For each run of the main experiment, the GLM contained eight regressors (four visibility conditions; objectively and subjectively visible and invisible, and two stimulus categories; faces and houses), as well as six motion regressors. Regressors were convolved with a standard hemodynamic response function, as included in SPM12. The resulting beta weights for each voxel were used as the data points for the following analyses. 
Multivoxel pattern analyses. Multivoxel pattern analysis (MVPA; using the CoSMoMVPA toolbo ${ }^{80}$ ) was used to identify brain regions carrying category-specific information in their activity patterns, i.e. activity that reliably distinguished between face and house stimuli. Activity patterns were correlated between the block-design localizer and the event-related main experiment. For every participant and for each of the four visibility conditions (obj-vis, subj-vis, subj-inv, obj-inv), betas from the localizer for one stimulus category (faces, houses) were correlated with betas from the main experiment for the same stimulus category, yielding within-category correlations, and with betas from the main experiment for the other stimulus category, yielding between-category correlations. Correlations were then Fisher $z$-transformed, the two within-category correlations were averaged, and the two between-category correlations were averaged. Finally, between-category correlations were subtracted from within-category correlations, yielding a correlation difference $\Delta r$ for each visibility condition ${ }^{49,50}$. Positive correlation differences indicate that activity patterns carry information about stimulus category.

Region-of-interest (ROI) analyses. Pattern correlation differences were calculated for four different (bilateral) ROIs. A probabilistic atlas of retinotopic cortex ${ }^{81}$ was used to define bilateral early visual cortex (V1). A functional group atlas ${ }^{82}$ was used to define bilateral lateral occipital complex (LOC), posterior category-selective areas (face-selective occipital face area OFA and scene-/houseselective occipital place area OPA [transverse occipital sulcus]), and anterior category-selective areas (face-selective fusiform face area FFA and scene-/house-selective parahippocampal place area PPA). For every participant, the localizer data were used to select the 100 most face-responsive and the 100 most house-responsive voxels within each of these ROIs (based on a $t$-test comparing face- and houseresponses; for similar results with other ROI definitions see Figure $\mathbf{S 3}$ and supplementary results).

Searchlight analyses. We additionally ran searchlight analyses ${ }^{52}$ to identify activity patterns that distinguished between categories across the whole brain. For these searchlights we repeatedly calculated pattern correlation differences in the same way as described for the ROI analyses but for a moving sphere with a radius of five voxels (524 voxels in each sphere) which was centered on every voxel in the functional images of every participant (for searchlight analyses based on the data from the main experiment only, see Supplementary material).

Controlling for mask contrast in the subjective condition. To control for trial-by-trial differences in mask contrast in the subjective condition, another GLM including a parametric regressor for mask contrast and an additional regressor for visibility, separately for faces and houses, was fit to the data from the subjective condition (all other aspects of the GLM were the same as described above). The visibility regressor was orthogonalized with respect to the mask-contrast regressor, such that the visibility regressor was assigned only the variance not explained by the mask-contrast regressor. Both 
bioRxiv preprint doi: https://doi.org/10.1101/2020.11.11.376681; this version posted November $11,2020$. The copyright holder for this preprint (which was not certified by peer review) is the author/funder, who has granted bioRxiv a license to display the preprint in perpetuity. It is made available under aCC-BY-ND 4.0 International license.

the mask-contrast and the visibility regressor were mean-centered (run-wise, separately for faces and houses).

Statistics. For behavior and ROI data, we report both standard frequentist statistics and Bayes factors (BFs) calculated in JASP ${ }^{83}$ with default prior scales (Cauchy distribution, scale 0.707). When frequentist statistics indicate a significant effect, the corresponding BF is reported as a quantification of the evidence for the alternative hypothesis $\left(\mathrm{BF}_{10}\right)$; when the effect is not significant, the reported $\mathrm{BF}$ quantifies the evidence for the null hypothesis $\left(\mathrm{BF}_{01}\right)$. To demonstrate absence of awareness in our objective measure, the directional $\mathrm{BF}_{0+}$ quantifies evidence for null sensitivity compared to the alternative of above-chance performance. For multi-factorial ANOVAs, we report the inclusion BF quantifying the evidence for all models containing a particular effect compared to all models without that effect. To test for category information in ROIs the directional $\mathrm{BF}_{+0}$ quantified evidence for abovechance information compared to the alternative of zero information. For the searchlight group maps results were corrected for multiple comparisons via false discovery rate (FDR) corrections ${ }^{53}(p<.05)$.

Data availability. The data sets generated during and/or analyzed during the current study are available from the corresponding author on request.

\section{Acknowledgments}

We thank T. Beemsterboer, T. Derckx, and S. Rasche for help with data collection, and L. Snoek for implementing the standardized "fMRIPrep" pipeline. This project has received funding from the European Research Council (ERC) under the European Union's Horizon 2020 research and innovation program (ERC-2016-STG_715605 to SvG), and from the German Research Foundation (DFG, KA4683/2-1 to DK). 
bioRxiv preprint doi: https://doi.org/10.1101/2020.11.11.376681; this version posted November 11, 2020. The copyright holder for this preprint (which was not certified by peer review) is the author/funder, who has granted bioRxiv a license to display the preprint in perpetuity. It is made available under aCC-BY-ND 4.0 International license.

\section{Supplementary Material}

Figure S1 shows individual stimulus exemplars used in the study (Figure S1a) and face-house discrimination performance as proportion correct in the $o b j$-inv condition for individual participants (Figure S1b and Figure S1c).

a

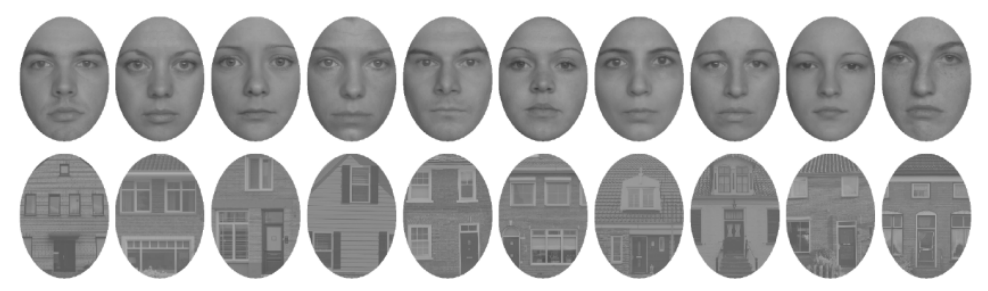

b

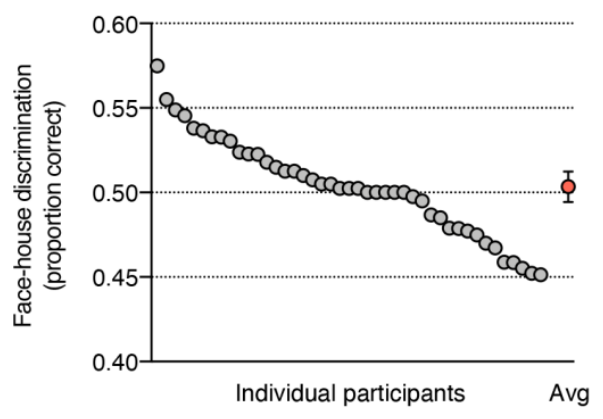

C

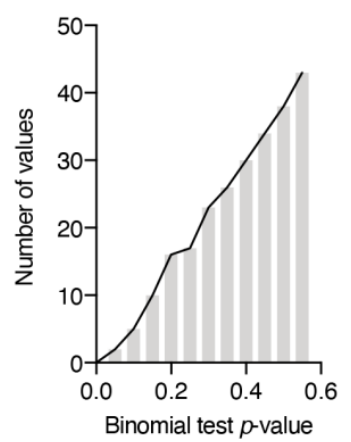

Figure S1. (a) Face and house exemplars used in the study. (b) Individual participant's face-house discrimination performance in the obj-inv condition as proportion correct. Every gray circle represents `a participant, the red circle shows the group mean with its $95 \%$ confidence interval. (c) Histogram showing the cumulative distribution of $p$-values from the one-sided binomial tests of face-house discrimination accuracy in the obj-inv condition.

\section{Evidence for objective invisibility}

For the interpretation of our fMRI results in our obj-inv condition it is important to test whether faces and houses were truly indiscriminable (objectively invisible). In the main manuscript, we report that discrimination performance $(M=0.02, S D=0.24)$ did not differ significantly from chance, with moderate evidence for the null hypothesis of chance-level discrimination $\left(t_{(42)}=0.45, p=.33\right.$ (onetailed), $\left.d_{z}=0.07, \mathrm{BF}_{0+}=4.13\right)$.

Standard statistical significance testing. Another approach that has been adopted in the literature on unconscious processing is to test every participant's performance against chance level Figure S1b shows face-house discrimination as proportion correct. One-tailed binomial tests comparing every participant's accuracy against the chance level of 0.5 revealed (only) one participant 
whose performance was significantly above the chance level $(p=.028)$. When carrying out 43 tests, some are expected to return a significant result. In fact, the distribution of $p$-values from the 43 binomial tests (Figure S1c) looks just as one would expect if values were randomly sampled from a binomial distribution with a probability of 0.5 success for each trial. However, as discussed in the main paper, although absence of awareness is commonly demonstrated by showing that performance did not exceed what is expected by chance $(p>.05)$, a non-significant result simply means that the observed effect is not very surprising under the null hypothesis of no effect, but cannot be taken as support for the null hypothesis.

Furthermore, $p$-values increase with decreasing power and increasing variance in the awareness measure, such that a non-significant result is not particularly surprising if the awareness measure is collected in few trials and small participant samples (i.e. with low power) ${ }^{74,75}$. To address these issues, we tested a much larger sample than previous fMRI studies, measured awareness in every trial during scanning (average of 196 trials per participant to calculate $d$ ' in the obj-inv condition), and did not exclude any participants based on their awareness data (which can severely inflate estimates of unconscious processing due to regression to the $\operatorname{mean}^{60}$ ). Although our fMRI study adopted the highest criteria for demonstrating unconscious processing of objectively invisible stimuli to date, approaches other than the standard frequentist significance-testing approach are required to provide evidence for absence of awareness. Two such alternative approaches are Bayesian statistics (as reported in the main paper) and equivalence tests.

Equivalence tests. Equivalence tests based on the two one-sided tests (TOST) procedure can be used to determine if an observed effect is surprisingly small under the assumption that a true effect, at least as large as a specific smallest effect size of interest (SESOI), exists ${ }^{84}$. In the context of unconscious processing, setting an SESOI represents a non-trivial, subjective call, as it requires determining the smallest $d$ ' score that can still reasonably be considered objectively invisible. Setting the SESOI (arbitrarily) to a $d^{\prime}$ 'score of 0.10 the TOST procedure (using the spreadsheet TOST calculators provided by Lakens and colleagues ${ }^{84}$ ) revealed that the observed effect was significant within the equivalent bounds of -0.1 and 0.1 scale points, $t_{(42)}=-2.23, p=.016$. We note that when setting the SESOI to a $d$ ' score of 0.15 , the TOST would return $p<.001$; when setting the SESOI to a $d$ ' score of 0.05 , however, the TOST would return $p=.19$. These results provide more insight about the uncertainty in our obj-inv data. While we cannot reasonably claim that discrimination performance was surprisingly low if the true effect was $d^{\prime}=0.05$, our data are unlikely if the true effect was $d^{\prime}=0.10$ or larger.

Bayesian statistics. The Bayesian statistical framework allows estimating how likely the observed data are under the null hypothesis, compared to the alternative hypothesis, and has thus particular utility in the study of unconscious processes ${ }^{59}$. While the null hypothesis in this framework is a point estimate (zero), Bayesian $t$-tests also require a non-trivial, subjective call in specifying the 
prior distribution for the alternative hypothesis. Estimates of the probability of the null hypothesis relative to the alternative hypothesis $\left(\mathrm{BF}_{0^{+}}\right)$depend on this prior. In the main paper, we used the default prior provided in the JASP software package (Cauchy distribution centered on zero and scale 0.707), and this resulted in "moderate" evidence for the null hypothesis $\left(\mathrm{BF}_{0+}=4.13\right)$. A wider prior (assigning more weight to larger effect sizes) would result in higher probability of the null hypothesis (e.g. with a Cauchy distribution with a scale of one, $\mathrm{BF}_{0+}=5.67$ ). Conversely, a narrower prior (assigning more weight to smaller effect sizes) would results in lower probability of the null hypothesis (e.g. with a normal distribution with $M=0$ and $S D=0.5, \mathrm{BF}_{0+}=2.34$ ). Rather than allowing definite conclusions about absence of awareness, our results highlight the statistical uncertainty inherent in demonstrations of unconscious processing, and invite discussions about reasonable prior assumptions and about which (bands of) effect sizes represent conclusive evidence for presence vs. absence of conscious awareness.

\section{Univariate ROI results}

We also conducted standard univariate ROI analyses (same ROI definitions as for the MVPA analyses). Here, for every participant and ROI we used the localizer data to determine the 100 most faceresponsive voxels and the 100 most house-selective voxels. We then calculated for every visibility condition in the main experiment the mean difference in activity evoked by faces vs. houses in the faceresponsive voxels and the mean difference in activity evoked by houses vs. faces in the house-responsive voxels. These differences were then averaged to yield a mean beta difference $(\Delta \beta)$ reflecting how well a region's activity in the main experiment distinguished its preferred category from the non-preferred category; $\Delta \beta$ was used as a univariate measure of category information. Univariate results were similar to the MVPA results reported in the main paper (compare Figure S2 with Figure 2).

Category information in visual cortex. As for the MVPA analyses, there were marked differences between the regions, with overall greater response differences in LOC than in $\operatorname{V1}\left(F_{(1,42)}=\right.$ $\left.156.82, p<.001, \eta_{p}^{2}=.79, \mathrm{BF}_{10}=1.35 \times 10^{22}\right)$, as well as response differences between visibility conditions $\left.F_{(3,126)}=56.44, p<.001, \eta_{p}{ }^{2}=.57, \mathrm{BF}_{10}=2.69 \times 10^{27}\right)$, and these differences were more pronounced in LOC than in V1 (interaction, $F_{(3,126)}=66.72, p<.001, \eta_{p}^{2}=.61, \mathrm{BF}_{10}=2.74 \times 10^{18}$ ). Separate one-tailed $t$-tests for every region and every visibility condition revealed significant category information in V1 for $o b j$ $\operatorname{vis}\left(t_{(42)}=3.57, p<.001, d_{z}=0.55, \mathrm{BF}_{+0}=65.68\right)$, subj-vis $\left(t_{(42)}=3.41, p<.001, d_{z}=0.52, \mathrm{BF}_{+0}=43.36\right)$, and obj-inv $\left(t_{(42)}=2.04, p=.024, d_{z}=0.31, \mathrm{BF}_{+0}=2.09\right)$, but not for subj-inv $\left(t_{(42)}=0.36, p=.36, d_{z}=\right.$ $\left.0.06, \mathrm{BF}_{0+}=4.48\right)$. LOC shoed significant category information in all visibility conditions, $o b j-v i s\left(t_{(42)}=\right.$ 22.77, $\left.p<.001, d_{z}=3.47, \mathrm{BF}_{+0}=2.18 \times 10^{22}\right)$, subj-vis $\left(t_{(42)}=12.11, p<.001, d_{z}=1.85, \mathrm{BF}_{+0}=4.79 \times 10^{12}\right)$, $\operatorname{subj-inv}\left(t_{(42)}=4.86, p<.001, d_{z}=0.74, \mathrm{BF}_{+0}=2.43 \times 10^{3}\right)$, and also in obj-inv $\left(t_{(42)}=3.17, p=.001, d_{z}=\right.$ $\left.0.48, \mathrm{BF}_{+0}=23.74\right)$. 
Similarly, for category-selective regions, category information was more pronounced in anterior (FFA/PPA) than in posterior (OFA/OPA) areas, $\left(F_{(1,42)}=111.32, p<.001, \eta_{p}^{2}=.73, \mathrm{BF}_{10}=1.23 \times 10^{18}\right)$; there were also significant differences between visibility conditions $\left(F_{(3,126}\right)=92.41, p<.001, \eta_{p}{ }^{2}=.69$, $\left.\mathrm{BF}_{10}=5.18 \times 10^{46}\right)$, and a significant interaction $\left(F_{(3,126)}=41.51, p<.001, \eta_{p}{ }^{2}=.50, \mathrm{BF}_{10}=4.25 \times 10^{9}\right) . \mathrm{In}$ OFA/OPA category information was significant in all conditions, obj-vis $\left(t_{(42)}=11.98, p<.001, d_{z}=1.82\right.$, $\left.\mathrm{BF}_{+0}=3.47 \times 10^{12}\right)$, subj-vis $\left(t(42)=7.47, p<.001, d_{z}=1.14, \mathrm{BF}_{+0}=7.61 \times 10^{6}\right)$, subj-inv $\left(t_{(42)}=4.30, p<\right.$ $\left..001, d_{z}=0.66, \mathrm{BF}_{+0}=478.01\right)$, and obj-inv $\left(t_{(42)}=2.96, p=.003, d_{z}=0.45, \mathrm{BF}_{+0}=14.37\right)$. Also in FFA $/ \mathrm{PPA}$ category information was significant in all visibility conditions, but as for the MVPA results, strong evidence for category information was obtained only for obj-vis $\left(t_{(42)}=15.92, p<.001, d_{z}=2.43, \mathrm{BF}_{+0}=\right.$ $\left.4.56 \times 10^{16}\right)$, subj-vis $\left(t_{(42)}=13.22, p<.001, d_{z}=2.02, \mathrm{BF}_{+0}=8.10 \times 10^{13}\right)$, and subj-inv $\left(t_{(42)}=6.04, p<.001\right.$, $\left.d_{z}=0.92, \mathrm{BF}_{+0}=8.95 \times 10^{4}\right)$, but not for obj-inv $\left(t_{(42)}=1.76, p=.043, d_{z}=0.27, \mathrm{BF}_{+0}=1.29\right)$.

Differences between visibility conditions. In both early visual cortex (V1) and object-selective visual cortex (LOC) subjective visibility was associated with greater category information than subjective invisibility $\left(\mathrm{V} 1: t_{(42)}=2.46, p=.018, d_{z}=0.38\right.$, but $\mathrm{BF}_{10}=2.39$; LOC: $t_{(42)}=8.44, p<.001, d_{z}=1.29, \mathrm{BF}_{10}$ $\left.=7.57 \times 10^{7}\right)$, but this difference was more pronounced in LOC (interaction, $F_{(1,42)}=34.79, p<.001, \eta_{p}{ }^{2}=$ $\left..45, \mathrm{BF}_{10}=1.22 \times 10^{3}\right)$. Also the way of establishing invisibility influenced the two areas differently (interaction, $F_{(1,42)}=9.83, p=.003, \eta_{p}{ }^{2}=.19, \mathrm{BF}_{10}=5.59$ ). While in $\mathrm{V} 1$ there was no significant difference in category information for subjectively and objectively invisible stimuli $\left(t_{(42)}=-1.26, p=.21, d_{z}=0.19\right.$, $\mathrm{BF}_{01}=2.89$ ), in LOC category information was significantly greater for subjectively than for objectively invisible stimuli $\left(t_{(42)}=2.27, p=.029, d_{z}=0.35\right.$, but $\left.\mathrm{BF}_{10}=1.64\right)$.

In both posterior and anterior category-selective regions subjective visibility was associated with greater category information than subjective invisibility (OFA/OPA: $t_{(42)}=4.24, p<.001, d_{z}=0.64$, $\mathrm{BF}_{10}=1.93 \times 10^{3}$; FFA/PPA: $\left.t_{(42)}=6.42, p<.001, d_{z}=0.98, \mathrm{BF}_{10}=2.73 \times 10^{7}\right)$, this difference was more pronounced in FFA/PPA (interaction, $F_{(1,42)}=21.05, p<.001, \eta_{p}{ }^{2}=.33, \mathrm{BF}_{10}=14.37$ ). Also the method of establishing invisibility had a different effect on the two ROIs (interaction, $F_{(1,42)}=23.01, p<.001, \eta_{p}^{2}$ $\left.=.35, \mathrm{BF}_{10}=62.34\right)$. While there was no significant difference between subjectively and objectively invisible stimuli in OFA/OPA $\left(t_{(42)}=0.79, p=.437, d_{z}=0.12, \mathrm{BF}_{01}=2.31\right)$, FFA/PPA showed greater category information for subjectively than for objectively invisible stimuli $\left(t_{(42)}=4.23, p<.001, d_{z}=0.64\right.$, $\left.\mathrm{BF}_{10}=597.15\right)$.

Posterior-anterior category preference gradient. The univariate ROI data also showed a posterior-anterior gradient (line plots in Figure S2). For obj-vis, subj-vis, and subj-inv category information increased from V1 to LOC (all $t_{(42)}>4.50, p<.001, d_{z}>0.59, \mathrm{BF}_{10}>75.25$, Figure S2a), and from OFA/OPA to FFA/PPA (all $t_{(42)}>5.11, p<.001, d_{z}>0.77, \mathrm{BF}_{10}=2.62 \times 10^{3}$, Figure S2b). For $o b j$-inv, this gradient was virtually absent; category information did not differ significantly between V1 and LOC 
bioRxiv preprint doi: https://doi.org/10.1101/2020.11.11.376681; this version posted November 11,2020 . The copyright holder for this preprint (which was not certified by peer review) is the author/funder, who has granted bioRxiv a license to display the preprint in perpetuity. It is made available under aCC-BY-ND 4.0 International license.

$\left(t_{(42)}=0.06, p=.95, d_{z}<0.01, \mathrm{BF}_{01}=6.05\right)$ or between OFA/OPA and FFA/PPA $\left(t_{(42)}=0.07, p=.95, d_{z}=\right.$ $\left.0.01, \mathrm{BF}_{01}=6.04\right)$.

a

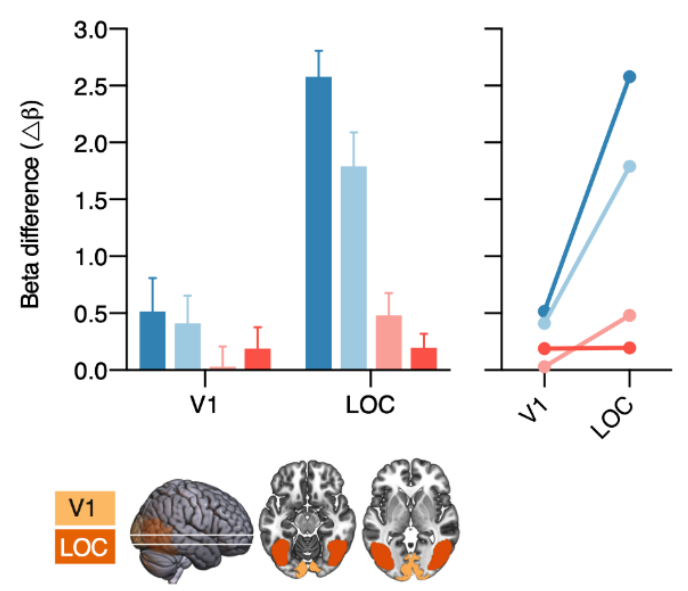

b

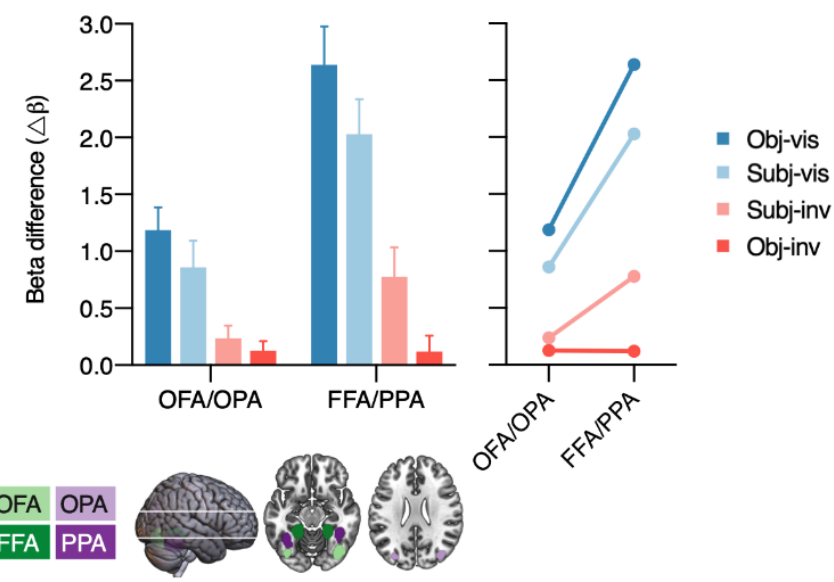

Figure S2. Univariate results. Responses to a voxel's preferred category vs. its non-preferred category (as determined by the independent localizer) for the four visibility conditions in the main experiment, averaged across the voxels in each brain region. Bars show the mean beta difference between preferred and nonpreferred categories $(\Delta \beta)$. Error bars represent 95\% confidence intervals. Line plots illustrate the anteriorposterior gradient in category information. (a) Results for early visual cortex (V1) vs. object-selective visual cortex (LOC). (b) Results for posterior category-selective areas (OFA/OPA) vs. anterior category-selective areas (FFA/PPA).

\section{Different ROI definitions}

For the univariate analyses and for the ROI analyses reported in the main paper we selected the 100 most face-responsive and the 100 most house-responsive voxels for each ROI, as determined by the localizer scan. To ensure that our results did not depend on this particular ROI size of 200 voxels, we repeated the MVPA correlation analyses for other ROI definitions (including between 10 [i.e. the 5 most face-responsive, and the 5 most house-responsive voxels in the localizer] and 500 voxels, in steps of 10). As can be seen in Figure S3, in all ROIs except for V1, overall pattern discrimination (category information $\Delta r$ ) dramatically increased with smaller ROI size. This was especially the case for the $o b j-$ vis and subj-vis conditions, and in LOC and in FFA/PPA also for subj-inv. ROI size had little influence on category information for the obj-inv condition. Most importantly, the patterns of differences between visibility conditions as reported in the main paper were robust across ROI definitions. 
bioRxiv preprint doi: https://doi.org/10.1101/2020.11.11.376681; this version posted November 11, 2020. The copyright holder for this preprint (which was not certified by peer review) is the author/funder, who has granted bioRxiv a license to display the preprint in perpetuity. It is made available under aCC-BY-ND 4.0 International license.

a

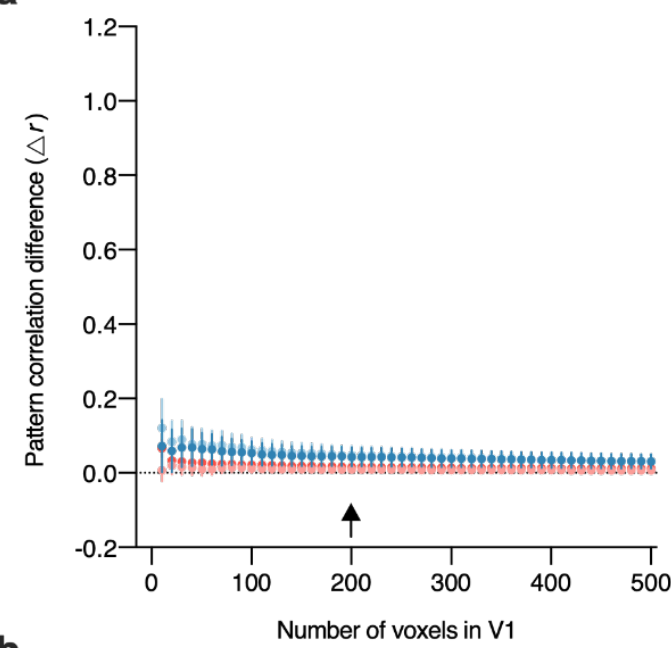

b

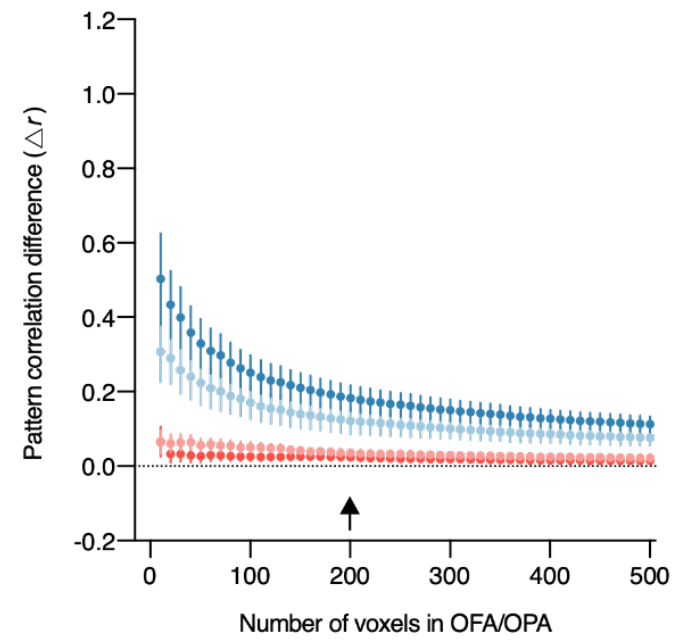

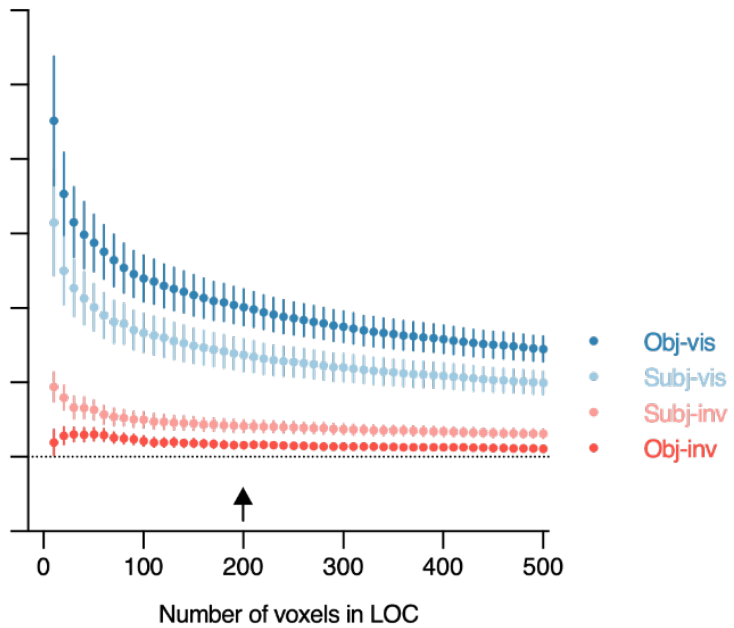

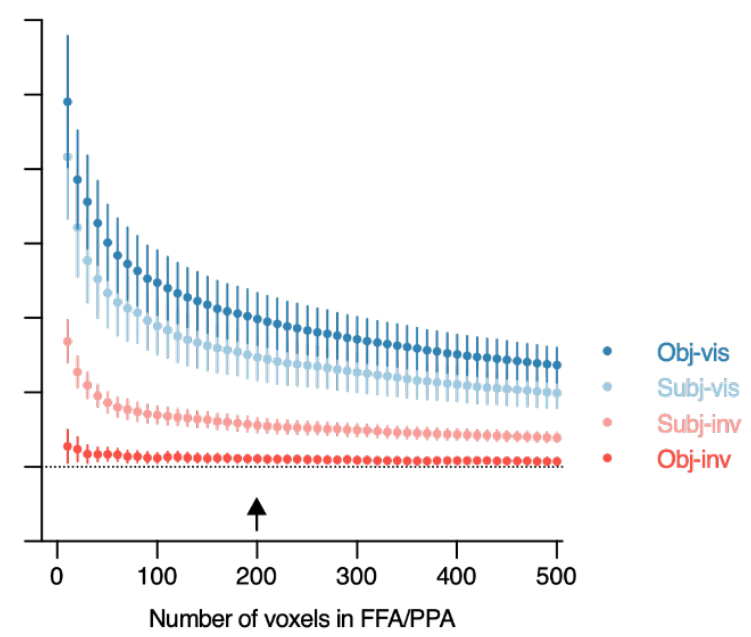

Figure S3. Category information in visual cortex. Multi-voxel pattern correlations between the four visibility conditions in the main experiment and the independent localizer, for a range of different ROI definitions (containing the 10 to 500 most face- and house-responsive voxels Symbols show the mean difference between within-category and between-category multi-voxel pattern correlations $(\Delta r)$. For better readability error bars represent SEMs. Arrows indicate the ROI definition adopted for the results presented in the main paper. (a) Results for early visual cortex (V1, left panel) vs. object-selective visual cortex (LOC, right panel). (b) Results for posterior category-selective areas (OFA/OPA, left panel) vs. anterior category-selective areas (FFA/PPA, right panel).

\section{Main-experiment searchlights}

All analyses reported in the main paper relate brain activity in the main experiment to the independent localizer scan, where participants did a simple one-back task on unmasked faces and houses presented for $750 \mathrm{~ms}$ each in a block design. We designed the study for this particular analysis strategy, because it is statistically powerful and isolates perceptual representations from later cognitive processes related to the task, decision, and motor processes ${ }^{49,50}$. Analyses based on the data from the main experiment alone 
bioRxiv preprint doi: https://doi.org/10.1101/2020.11.11.376681; this version posted November $11,2020$. The copyright holder for this preprint (which was not certified by peer review) is the author/funder, who has granted bioRxiv a license to display the preprint in perpetuity. It is made available under aCC-BY-ND 4.0 International license.

cannot exclude such influences, for example, in these analyses button presses are confounded with the different stimulus and visibility conditions.

Category information. Accordingly, additional searchlight analyses based on the mainexperiment data alone revealed category information in motor cortex, driven by the responses given to the presented categories (Figure S3). For these searchlights, the main experiment data were split into two sets (all possible splits of two and three runs). For every visibility conditions we repeatedly calculated within- and between-category pattern correlation differences for a moving sphere with a radius of five voxels (524 voxels in the sphere) which was centered on every voxel in the functional images of every participant. Correlations from all possible splits were then averaged to yield the searchlight maps.

These analyses revealed areas carrying significant category information across the whole brain (corrected for multiple comparisons via false discovery estimation, $p<.05$ ) in the obj-vis, subj-vis, and subj-inv condition, but not in the obj-inv condition (Figure S3a). In all three visibility conditions clusters with significant category information were located in bilateral fusiform gyrus, but most prominently in bilateral motor cortex (highlighted in the slices shown in Figure S3a). Such motor cortex pattern discrimination reflects the correlation between stimulus category and participant's button presses for those conditions in which button presses (perceptual discrimination) carried information about stimulus category (when discrimination performance is above chance). Accordingly, additional frontal cortex clusters (in right inferior frontal gyrus, orbital parts of right superior and left middle frontal gyrus) revealed in the contrast between subj-inv and subj-vis (Figure S3b) are difficult to interpret. Remarkably, there was no evidence for category information in motor cortex in the obj-inv condition, indicating that in this condition (neural representations of) button presses were indeed unrelated to stimulus category, thus further supporting the notion that stimuli were fully indiscriminable. 
a Obj-vis Subj-vis
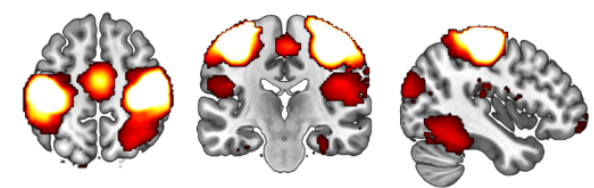

Subj-inv
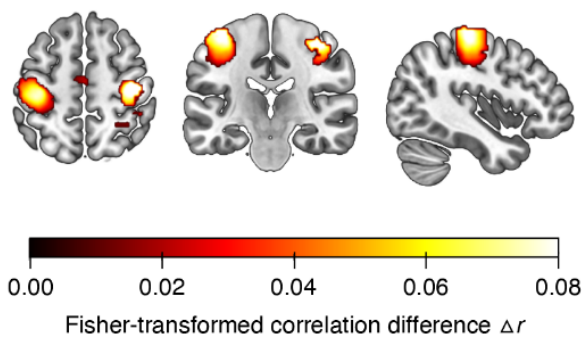

b
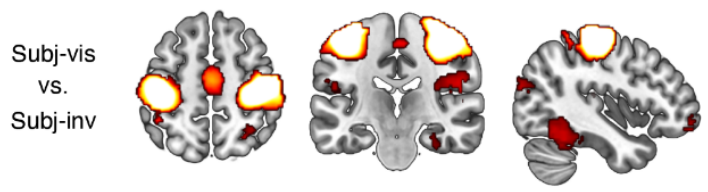

Subj-inv
vs.

Obj-inv
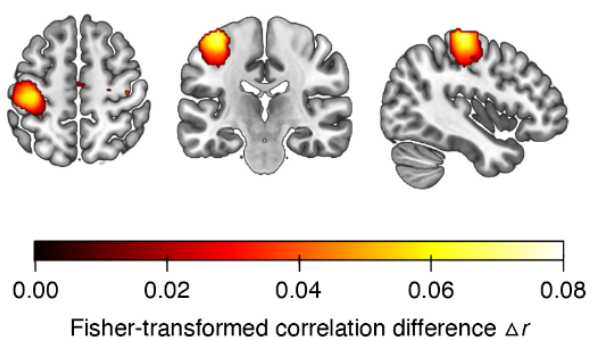

Figure S3. (a) Results from the additional searchlight analyses of the main experiment only, showing clusters with significant category information across the whole brain, separately for the different visibility conditions. Slices were selected to highlight motor cortex. Only voxels surviving multiple comparison correction via false discovery estimation ${ }^{53}(p<.05)$ are shown. For the objectively invisible condition, no clusters survived this statistical threshold. (b) Searchlight results showing the effect of subjective visibility by comparing the subjvis to the subj-inv condition, and the effect of method for establishing invisibility by comparing the subj-inv to the obj-inv condition.

Visibility irrespective of category. In addition to occipitotemporal areas, several previous fMRI studies reported correlates of conscious visual perception in a frontoparietal network ${ }^{5,11}$.These studies compared brain activity evoked by visible and invisible conditions, independent of stimulus category or content, assessing visibility either with objective measures (e.g. by comparing weakly vs. strongly masked stimuli ${ }^{40}$ ) or with subjective measures of visibility (e.g. by comparing similar or identical stimuli judged as "visible" vs. "invisible" ${ }^{11}$ ). To test for such frontoparietal involvement in content-independent conscious perception ("conscious access" or "report"), we conducted searchlight analyses that revealed brain areas where activity distinguished between visibility conditions, independent of object category. For these searchlights, we again split the main experiment data into two sets (all possible splits of two and three runs). Separately for the objective and for the subjective condition we repeatedly calculated within-visibility (visible/visible and invisible/invisible) and between-visibility (visible/invisible) pattern correlations for a moving sphere with a radius of five voxels (524 voxels in the sphere) which was centered on every voxel in the functional images of every participant. Correlations from all possible splits were then averaged to yield the searchlight maps. 
bioRxiv preprint doi: https://doi.org/10.1101/2020.11.11.376681; this version posted November 11,2020 . The copyright holder for this preprint (which was not certified by peer review) is the author/funder, who has granted bioRxiv a license to display the preprint in perpetuity. It is made available under aCC-BY-ND 4.0 International license.

In both the objective and subjective condition activity in many brain areas distinguished between visible and invisible trials (corrected for multiple comparisons via false discovery estimation, $p$ $<.05$ ), including early visual cortex, fusiform and inferior temporal gyrus, parietal cortex (e.g. inferior parietal lobule, precuneus, angular gyrus, postcentral gyrus), frontal cortex (e.g. motor cortex, inferior frontal gyrus, superior frontal gyrus, middle frontal gyrus, anterior cingulate), and anterior cingulate cortex. The sagittal views of the right hemisphere in Figure $\mathbf{4} 4$ highlight significant pattern correlations in ventrotemporal areas, parietal cortex, and inferior frontal gyrus in both objective and subjective conditions. These results could be considered evidence for frontoparietal involvement in (contentindependent) conscious perception. Note, however, that in these analyses based on the main-experiment data, post-perceptual processes (related to the task, decision, and motor processes) and stimulus strength (mask contrast) are confounded with differences in visibility.

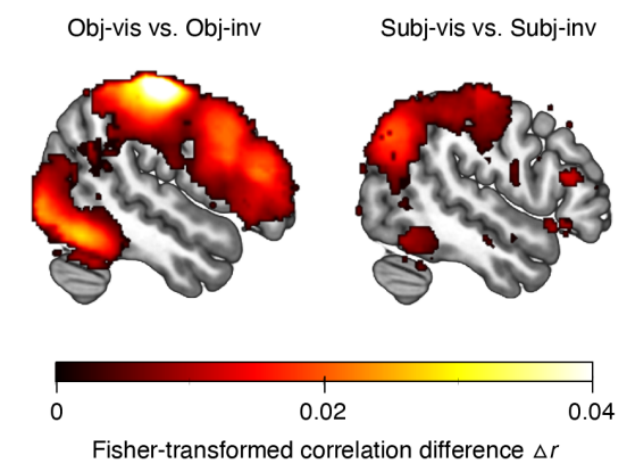

Figure S4. Results from searchlight analyses of the main experiment only, showing clusters with significant information about stimulus visibility across the whole brain (independent of stimulus category), separately for the objective condition (comparing obj-vis to obj-inv) and for the subjective condition (comparing subj-vis to subj-inv). Slices show the right hemisphere and were selected to highlight ventrotemporal regions, parietal cortex, and inferior frontal gyrus in both conditions. Only voxels surviving multiple comparison correction via false discovery estimation ${ }^{53}(p<.05)$ are shown. 
bioRxiv preprint doi: https://doi.org/10.1101/2020.11.11.376681; this version posted November 11, 2020. The copyright holder for this preprint (which was not certified by peer review) is the author/funder, who has granted bioRxiv a license to display the preprint in perpetuity. It is made available under aCC-BY-ND 4.0 International license.

SUBJECTIVE VS. OBJECTIVE MEASURES OF CONSCIOUSNESS

\section{References}

1. Dehaene, S., Lau, H. \& Kouider, S. What is consciousness, and could machines have it? Science 358, 486-492 (2017).

2. LeDoux, J. E., Michel, M. \& Lau, H. A little history goes a long way toward understanding why we study consciousness the way we do today. Proc. Natl. Acad. Sci. 117, 6976-6984 (2020).

3. Seth, A. K. Consciousness: The last 50 years (and the next). Brain Neurosci. Adv. 2, 1-6 (2018).

4. Doerig, A., Schurger, A. \& Herzog, M. H. Hard criteria for empirical theories of consciousness. Cognitive Neuroscience 1-22 (2020) doi:10.1080/17588928.2020.1772214.

5. Dehaene, S., Changeux, J. P., Naccache, L., Sackur, J. \& Sergent, C. Conscious, preconscious, and subliminal processing: A testable taxonomy. Trends Cogn. Sci. 10, 204-211 (2006).

6. Lamme, V. A. F. Why visual attention and awareness are different. Trends Cogn. Sci. 7, 12-18 (2003).

7. Lau, H. \& Rosenthal, D. Empirical support for higher-order theories of conscious awareness. Trends Cogn. Sci. 15, 365-373 (2011).

8. Hesselmann, G. \& Moors, P. Definitely maybe: Can unconscious processes perform the same functions as conscious processes? Front. Psychol. 6, 584 (2015).

9. Moors, P., Hesselmann, G., Wagemans, J. \& van Ee, R. Continuous Flash Suppression: Stimulus Fractionation rather than Integration. Trends Cogn. Sci. 21, 719-721 (2017).

10. Sterzer, P., Stein, T., Ludwig, K., Rothkirch, M. \& Hesselmann, G. Neural processing of visual information under interocular suppression: A critical review. Front. Psychol. 5, 453 (2014).

11. Rees, G. Neural correlates of the contents of visual awareness in humans. Philos. Trans. R. Soc. B Biol. Sci. 362, 877-886 (2007).

12. Kouider, S. \& Dehaene, S. Levels of processing during non-conscious perception: A critical review of visual masking. Philos. Trans. R. Soc. B Biol. Sci. 362, 857-875 (2007).

13. Hassin, R. R. Yes it can: On the functional abilities of the human unconscious. Perspect. Psychol. Sci. 8, 195-207 (2013).

14. Sklar, A. Y. et al. Reading and doing arithmetic nonconsciously. Proc. Natl. Acad. Sci. U. S. A. 109, 19614-19619 (2012).

15. Hesselmann, G. Dissecting visual awareness with fMRI. Neuroscientist 19, 495-508 (2013).

16. Ramsøy, T. Z. \& Overgaard, M. Introspection and subliminal perception. Phenomenol. Cogn. Sci. 3, 1-23 (2004).

17. Marois, R., Yi, D. J. \& Chun, M. M. The Neural Fate of Consciously Perceived and Missed Events in the Attentional Blink. Neuron 41, 465-472 (2004).

18. Beck, D. M., Rees, G., Frith, C. D. \& Lavie, N. Neural correlates of change detection and change blindness. Nat. Neurosci. 4, 645-650 (2001). 
bioRxiv preprint doi: https://doi.org/10.1101/2020.11.11.376681; this version posted November $11,2020$. The copyright holder for this preprint (which was not certified by peer review) is the author/funder, who has granted bioRxiv a license to display the preprint in perpetuity. It is made available under aCC-BY-ND 4.0 International license.

19. King, J. R., Pescetelli, N. \& Dehaene, S. Brain Mechanisms Underlying the Brief Maintenance of Seen and Unseen Sensory Information. Neuron 92, 1122-1134 (2016).

20. Trübutschek, D. et al. A theory of working memory without consciousness or sustained activity. Elife 6, (2017).

21. Trübutschek, D., Marti, S., Ueberschär, H. \& Dehaene, S. Probing the limits of activity-silent non-conscious working memory. Proc. Natl. Acad. Sci. U. S. A. 116, 14358-14367 (2019).

22. Soto, D., Mäntylä, T. \& Silvanto, J. Working memory without consciousness. Curr. Biol. 21, R912-R913 (2011).

23. Bergström, F. \& Eriksson, J. The conjunction of non-consciously perceived object identity and spatial position can be retained during a visual short-term memory task. Front. Psychol. 6, 1470 (2015).

24. Hesselmann, G., Hebart, M. \& Malach, R. Differential BOLD activity associated with subjective and objective reports during 'blindsight' in normal observers. J. Neurosci. 31, 12936-12944 (2011).

25. Schmidt, T. Invisible stimuli, implicit thresholds: Why invisibility judgments cannot be interpreted in isolation. Adv. Cogn. Psychol. 11, 31-41 (2015).

26. Macmillan, N. A. \& Creelman, C. D. Detection theory: A user's guide. (Lawrence Erlbaum, 2005).

27. Björkman, M., Juslin, P. \& Winman, A. Realism of confidence in sensory discrimination: The underconfidence phenomenon. Percept. Psychophys. 54, 75-81 (1993).

28. Peters, M. A. K. \& Lau, H. Human observers have optimal introspective access to perceptual processes even for visually masked stimuli. Elife 4, e09651 (2015).

29. Eriksen, C. W. Discrimination and learning without awareness: A methodological survey and evaluation. Psychol. Rev. 67, 279-300 (1960).

30. Holender, D. Semantic activation without conscious identification in dichotic listening, parafoveal vision, and visual masking: A survey and appraisal. Behav. Brain Sci. 9, 1-23 (1986).

31. Schmidt, T. \& Vorberg, D. Criteria for unconscious cognition: Three types of dissociation. Percept. Psychophys. 68, 489-504 (2006).

32. Sterzer, P., Haynes, J. D. \& Rees, G. Fine-scale activity patterns in high-level visual areas encode the category of invisible objects. J. Vis. 8, 1-12 (2008).

33. Haynes, J. D. \& Rees, G. Predicting the orientation of invisible stimuli from activity in human primary visual cortex. Nat. Neurosci. 8, 686-691 (2005).

34. Jiang, Y., Zhou, K. \& He, S. Human visual cortex responds to invisible chromatic flicker. Nat. Neurosci. 10, 657-662 (2007).

35. Jiang, Y. \& He, S. Cortical Responses to Invisible Faces: Dissociating Subsystems for FacialInformation Processing. Curr. Biol. 16, 2023-2029 (2006). 
bioRxiv preprint doi: https://doi.org/10.1101/2020.11.11.376681; this version posted November $11,2020$. The copyright holder for this preprint (which was not certified by peer review) is the author/funder, who has granted bioRxiv a license to display the preprint in perpetuity. It is made available under aCC-BY-ND 4.0 International license.

36. Moutoussis, K. \& Zeki, S. The relationship between cortical activation and perception investigated with invisible stimuli. Proc. Natl. Acad. Sci. U. S. A. 99, 9527-9532 (2002).

37. Fang, F. \& He, S. Cortical responses to invisible objects in the human dorsal and ventral pathways. Nat. Neurosci. 8, 1380-1385 (2005).

38. Fahrenfort, J. J. et al. Neuronal integration in visual cortex elevates face category tuning to conscious face perception. Proc. Natl. Acad. Sci. U. S. A. 109, 21504-21509 (2012).

39. Dehaene, S. et al. Conscious and subliminal conflicts in normal subjects and patients with schizophrenia: The role of the anterior cingulate. Proc. Natl. Acad. Sci. U. S. A. 100, 13722-13727 (2003).

40. Dehaene, S. et al. Cerebral mechanisms of word masking and unconscious repetition priming. Nat. Neurosci. 4, 752-758 (2001).

41. Van Gaal, S., Ridderinkhof, K. R., Scholte, H. S. \& Lamme, V. A. F. Unconscious activation of the prefrontal no-go network. J. Neurosci. (2010) doi:10.1523/JNEUROSCI.2992-09.2010.

42. Reingold, E. M. \& Merikle, P. M. Using direct and indirect measures to study perception without awareness. Percept. Psychophys. 44, 563-575 (1988).

43. Malach, R. et al. Object-related activity revealed by functional magnetic resonance imaging in human occipital cortex. Proc. Natl. Acad. Sci. U. S. A. 92, 8135-8139 (1995).

44. Pourtois, G., Schwartz, S., Spiridon, M., Martuzzi, R. \& Vuilleumier, P. Object representations for multiple visual categories overlap in lateral occipital and medial fusiform cortex. Cereb. Cortex August 19, 1806-1819 (2009).

45. Pitcher, D., Walsh, V. \& Duchaine, B. The role of the occipital face area in the cortical face perception network. Exp. Brain Res. 209, 481-493 (2011).

46. Dilks, D. D., Julian, J. B., Paunov, A. M. \& Kanwisher, N. The occipital place area is causally and selectively involved in scene perception. J. Neurosci. 33, 1331-1336 (2013).

47. Kanwisher, N. Functional specificity in the human brain: A window into the functional architecture of the mind. Proc. Natl. Acad. Sci. U. S. A. 107, 11163-11170 (2010).

48. Wagenmakers, E. J. et al. Bayesian inference for psychology. Part II: Example applications with JASP. Psychon. Bull. Rev. 25, 58-76 (2018).

49. Peelen, M. V., Fei-Fei, L. \& Kastner, S. Neural mechanisms of rapid natural scene categorization in human visual cortex. Nature 460, 94-97 (2009).

50. Peelen, M. V. \& Kastner, S. A neural basis for real-world visual search in human occipitotemporal cortex. Proc. Natl. Acad. Sci. U. S. A. 108, 12125-12130 (2011).

51. Kamps, F. S., Julian, J. B., Kubilius, J., Kanwisher, N. \& Dilks, D. D. The occipital place area represents the local elements of scenes. Neuroimage 132, 417-424 (2016).

52. Kriegeskorte, N., Goebel, R. \& Bandettini, P. Information-based functional brain mapping. Proc. 
bioRxiv preprint doi: https://doi.org/10.1101/2020.11.11.376681; this version posted November $11,2020$. The copyright holder for this preprint (which was not certified by peer review) is the author/funder, who has granted bioRxiv a license to display the preprint in perpetuity. It is made available under aCC-BY-ND 4.0 International license.

Natl. Acad. Sci. U. S. A. 103, 3863-3868 (2006).

53. Benjamini, Y. \& Hochberg, Y. Controlling the false discovery rate: A practical and powerful approach to multiple testing. J. R. Stat. Soc. Ser. B 57, 289-300 (1995).

54. Mumford, J. A., Poline, J.-B. \& Poldrack, R. A. Orthogonalization of regressors in fMRI models. PLoS One 10, e0126255 (2015).

55. Azzopardi, P. \& Cowey, A. Is blindsight like normal, near-threshold vision? Proc. Natl. Acad. Sci. U. S. A. 94, 14190-14194 (1997).

56. Rodríguez, V. et al. Absence of face-specific cortical activity in the complete absence of awareness: Converging evidence from functional magnetic resonance imaging and eventRelated potentials. J. Cogn. Neurosci. 24, 396-415 (2012).

57. Gayet, S. et al. No evidence for mnemonic modulation of interocularly suppressed visual input. Neuroimage 215, 116801 (2020).

58. Ludwig, K., Kathmann, N., Sterzer, P. \& Hesselmann, G. Investigating category- and shapeselective neural processing in ventral and dorsal visual stream under interocular suppression. Hum. Brain Mapp. 36, 137-149 (2015).

59. Dienes, Z. How Bayesian statistics are needed to determine whether mental states are unconscious. in Behavioral Methods in Consciousness Research (ed. Overgaard, M.) 199-220 (Oxford Academic, 2015).

60. Shanks, D. R. Regressive research: The pitfalls of post hoc data selection in the study of unconscious mental processes. Psychon. Bull. Rev. 24, 752-775 (2017).

61. Stein, T., Utz, V. \& van Opstal, F. Unconscious semantic priming from pictures under backward masking and continuous flash suppression. Conscious. Cogn. 78, 102864 (2020).

62. Van Den Bussche, E., Notebaert, K. \& Reynvoet, B. Masked primes can be genuinely semantically processed: A picture prime study. Exp. Psychol. 56, 295-300 (2009).

63. Vorberg, D., Mattler, U., Heinecke, A., Schmidt, T. \& Schwarzbach, J. Different time courses for visual perception and action priming. Proc. Natl. Acad. Sci. U. S. A. 100, 6275-6280 (2003).

64. Klotz, W. \& Neumann, O. Motor activation without conscious discrimination in metacontrast masking. J. Exp. Psychol. Hum. Percept. Perform. 25, 976-992 (1999).

65. Cheesman, J. \& Merikle, P. M. Priming with and without awareness. Percept. Psychophys. 36, 387-395 (1984).

66. Scott, R. B., Samaha, J., Chrisley, R. \& Dienes, Z. Prevailing theories of consciousness are challenged by novel cross-modal associations acquired between subliminal stimuli. Cognition 175, 169-185 (2018).

67. Soto, D. \& Silvanto, J. Reappraising the relationship between working memory and conscious awareness. Trends Cogn. Sci. 18, 520-525 (2014). 
bioRxiv preprint doi: https://doi.org/10.1101/2020.11.11.376681; this version posted November $11,2020$. The copyright holder for this preprint (which was not certified by peer review) is the author/funder, who has granted bioRxiv a license to display the preprint in perpetuity. It is made available under aCC-BY-ND 4.0 International license.

68. Zeki, S. A Theory of Micro-Consciousness. in The Blackwell Companion to Consciousness 580588 (Blackwell Publishing, 2007).

69. Malach, R. The measurement problem in consciousness research. Behav. Brain Sci. 30, 516-517 (2007).

70. Koch, C., Massimini, M., Boly, M. \& Tononi, G. Neural correlates of consciousness: Progress and problems. Nat. Rev. Neurosci. 17, 307-321 (2016).

71. Mashour, G. A., Roelfsema, P., Changeux, J. P. \& Dehaene, S. Conscious processing and the global neuronal workspace hypothesis. Neuron 105, 776-798 (2020).

72. Tsuchiya, N., Wilke, M., Frässle, S. \& Lamme, V. A. F. No-report paradigms: Extracting the true neural correlates of consciousness. Trends Cogn. Sci. 19, 757-770 (2015).

73. Button, K. S. et al. Power failure: Why small sample size undermines the reliability of neuroscience. Nat. Rev. Neurosci. 14, 365-376 (2013).

74. Vadillo, M. A., Linssen, D., Orgaz, C., Parsons, S. \& Shanks, D. R. Unconscious or underpowered? Probabilistic cuing of visual attention. J. Exp. Psychol. Gen. 149, 160-181 (2020).

75. Vadillo, M. A., Konstantinidis, E. \& Shanks, D. R. Underpowered samples, false negatives, and unconscious learning. Psychon. Bull. Rev. 23, 87-102 (2016).

76. Brainard, D. H. The psychophysics toolbox. Spat. Vis. 10, 433-436 (1997).

77. Ebner, N. C., Riediger, M. \& Lindenberger, U. FACES-a database of facial expressions in young, middle-aged, and older women and men: Development and validation. Behav. Res. Methods $\mathbf{4 2}$, $351-362$ (2010).

78. Esteban, O. et al. fMRIPrep: A robust preprocessing pipeline for functional MRI. Nat. Methods 16, 111-116 (2019).

79. Fonov, V., Evans, A., McKinstry, R., Almli, C. \& Collins, D. Unbiased nonlinear average ageappropriate brain templates from birth to adulthood. Neuroimage 47, S102 (2009).

80. Oosterhof, N. N., Connolly, A. C. \& Haxby, J. V. CoSMoMVPA: Multi-modal multivariate pattern analysis of neuroimaging data in matlab/GNU octave. Front. Neuroinform. 10, 10-27 (2016).

81. Wang, L., Mruczek, R. E. B., Arcaro, M. J. \& Kastner, S. Probabilistic Maps of Visual Topography in Human Cortex. Cereb. Cortex 25, 3911-3931 (2015).

82. Julian, J. B., Fedorenko, E., Webster, J. \& Kanwisher, N. An algorithmic method for functionally defining regions of interest in the ventral visual pathway. Neuroimage 60, 2357-2364 (2012).

83. JASP Team. JASP (Version 0.12.2)[Computer software]. (2020).

84. Lakens, D., Scheel, A. M. \& Isager, P. M. Equivalence testing for psychological research: A tutorial. Adv. Methods Pract. Psychol. Sci. 1, 259-269 (2018). 